\title{
$1 \quad$ Plasmotype condition nuclear pleiotropic effects on clock and fitness in barley
}

2

3 Corresponding author:

4 Eyal Fridman

5 Plant Sciences Institute, Volcani Agricultural Research Organization (ARO), Bet

6 Dagan, Israel

7

8 Tel: +97239683901

9 Fax: +97239669583

10

11 Running title: Cytonuclear control of clock and fitness in barley

12

13 Eyal Bdolach ${ }^{1,2}$, Manas Ranjan Prusty ${ }^{1}$, Lalit Dev Tiwari ${ }^{1}$, Khalil Kashkush ${ }^{2}$, Eyal 14 Fridman $^{1}$

${ }^{1}$ Plant Sciences Institute, Volcani Agricultural Research Organization (ARO), Bet

17 Dagan, Israel

$18{ }^{2}$ Department of Life Sciences, Ben-Gurion University, 84105, Beer-Sheva, Israel 19

Analyzing barley populations that segregate for plasmotype and nucleotype diversity

21 we demonstrate how the clock is associated with cytonuclear diversity and with

22 pleiotropic effects on fitness

24 This work was supported by grants from the Israel Science Foundation (ISF 444/21)

25 and Horizon2020/CAPITALISE AMD-862201-2 grants to E.F.

27 Corresponding author email: fridmane@agri.gov.il

28

29

30

31

32

33

ABSTRACT 
35 In plants, the role of chloroplasts and mitochondria (plasmotype) in controlling circadian clock plasticity and overall plant robustness has not been elucidated. In this study, we investigated the rhythmicity of chlorophyll fluorescence (Chl F) clock output, and fitness in the field at optimal and elevated temperatures, in three different barley populations. First, we examined a reciprocal DH population between two wild barley (Hordeum vulgare ssp. spontaneum), in which we identified two pleiotropic QTLs (frp2.1 and amp7.1) that modulate clock and fitness including conditioning of these effects by plasmotype diversity. In the second population, a complete diallel

43 consisting of 11 genotypes (reciprocal hybrids differing in plasmotype), we observed 44 a gradual reduction in plasmotype, ranging from $26 \%$ and $15 \%$ for $\mathrm{Chl} \mathrm{F}$ and clock measurements to $5.3 \%$ and $3.7 \%$ for growth and reproductive traits, respectively. The third population studied was a collection of cytolines in which nine different wild plasmotypes replaced the cultivated Noga ( $H$. vulgare) plasmotype. Here, the order and magnitude of the effects of the plasmotypes differed from what we observed in the diallel population, with the greatest effect of plasmotype diversity observed for clock period and amplitude. Comparison of the chloroplast sequences suggests several

51 candidate genes in the plastid-encoded RNA polymerase (PEP) complex that may be responsible for the observed plasmotype effects. Overall, our results unravel previously unknown cytonuclear epistatic interactions that controls clock performance while also having pleiotropic effects on a plant field characteristics. 


\section{INTRODUCTION}

Plants are composed of cells in which three different organelle genomes coevolved to cope with a dynamic environment: the genomes in nuclei, chloroplast and mitochondria (plasmotype). Phenotypic constraints promote selection of causal mutations in those three genomes and at the same time, interactions between genome products may impose epistatic relationship and co-evolution of adaptive gene complexes. In recent years, several studies have shown that phenotypic effects are related to the genetic diversity of the plasmotype and its interactions with the nucleotype (Joseph et al, 2013; Roux et al, 2016; Tang et al, 2014). An elegant use of haploid-inducer line available in Arabidopsis (GFP-tailswap) (Ravi et al., 2014) allowed generating a set of reciprocal and isogenic cybrids using several accessions, which was followed by phenotyping of metabolism and photosynthesis under different light conditions (Flood et al., 2020). Genetic analysis revealed that the nucleotype, plasmotype and their interaction accounted for 91.9, 2.9 and 5.2\% of genetic variation, respectively, thus highlighting the importance of interactions between genomes. Moreover, variation explained due to cytonuclear epistasis was even higher $(17.8 \%)$ for $\Phi_{\mathrm{NPQ}}$ and changed significantly between different light regimes.

In crop plants, few reports exist on the contribution of cytonuclear interactions (CNI) to a plant's phenotype, and even less to its effects on the plant's phenotypic plasticity. Especially in grasses, the contribution of the plasmotype to yield and grain quality has been demonstrated (Frei et al., 2003; Sanetomo and Gebhardt, 2015). In cucumber, Gordon and Staub (2011) used reciprocal backcrosses between chillingsensitive and chilling-tolerant lines to show that tolerance to reduced temperature is maternally inherited. Likely these traits are the result of a local adaption of the original wild alleles, since for example in bread wheat (Trictium aestivum) cytoplasmic influence on fruit quality is affected by genotype-by-environment interactions (Ekiz et al., 1998). Nevertheless, many of these examinations of alloplasmic lines, which contained cytoplasm from distantly related wild relatives showed that effects on agronomic traits (rather than protein quality) are not frequent (Frei et al., 2010). In maize, although cytoplasmic effects were not significant between the direct and reciprocal populations, the interactions among the cytoplasm and the nuclear quantitative trait loci (QTL) were detected for both days to tassel, and days to pollen shed (Tang et al., 2014), further enforcing the increased variation 
91 explained in Arabidopsis cybrids when cytonuclear interactions are included (Flood et

92

93

94 al., 2020).

3 Circadian clock rhythms in plants are interwind with chloroplastic activities including photosynthetic phenotypes such as NPQ and ФPSII that are important for plant productivity (Kromdijk et al., 2016). This connection led to the development of several high-throughput methods that measure the rhythmicity of the leaf chlorophyll fluorescence as a proxy to the period, phase and amplitude of the clock (Gould et al., 2009; Tindall et al., 2015; Dakhiya et al., 2017;). The ability to measure hundreds of plants allowed comparisons between species (Rees et al., 2019), identification of correlation for period and amplitude with temperature and soil composition (Dakhiya et al., 2017), as well as associating between naturally occurring circadian rhythm variation with clock gene loci in Swedish Arabidopsis accessions (Rees et al., 2021). Using the SensyPAM platform, which allows to infer clock output rhythmicity based on photosynthetic parameters (Bdolach et al., 2019), we recently analyzed wild, landraces, cultivars and interspecific barley populations. We showed that some of the nuclear loci that control the circadian rhythms were under selection during domestication, which could explain how modern crops lost the thermal plasticity of their clock (Prusty et al., 2021). Furthermore, pleiotropic effects of these drivers of clock (DOC) loci on grain yield under stress indicate the adaptive value of clock plasticity although the molecular, developmental, and physiological basis of this pleiotropy requires more experiments. Moreover, this study did not consider the possible role of cytoplasm diversity in manifesting these clock and pleiotropic effects on growth and reproductive fitness traits.

Here we follow up on the clock analysis of a reciprocal bi-parental doubled haploid $(\mathrm{DH})$ population divided between genotypes carrying different plasmotypes from the Barley1K collection (from Ashkelon or Mount Hermon) (Hubner et al., 2009), and segregating for their nuclear genomes as well. We previously showed a significant difference of $2.2 \mathrm{~h}$ in the clock plasticity (delta of period) between the carriers of the different plasmotypes (Bdolach et al., 2019). In addition, we identified several nucleotype QTL that affected the period or the amplitude of the rhythmicity, based on $\Phi N P Q 1 s s$ measurements. In the current study, we intend to 1) extend the analysis of the plasmotype effects on fitness traits and test if there is pleiotropy between clock and life history traits, and 2) to extend the breadth of plasmotype diversity tested by adding additional crosses and more chloroplast sequencing 
bioRxiv preprint doi: https://doi.org/10.1101/2021.11.02.466976; this version posted November 2, 2021. The copyright holder for this preprint (which was not certified by peer review) is the author/funder, who has granted bioRxiv a license to display the preprint in perpetuity. It is made available under aCC-BY-NC-ND 4.0 International license.

125 information, and finally 3) to examine the potential of wild plasmotype diversity for 126 modern crop breeding under optimal and high temperature.

127

128 
129

130

131

132

133

134

135

136

137

138

139

140

141

142

143

144

145

146

147

148

149

150

151

152

153

154

155

156

157

158

159

160

161

162

\section{RESULTS}

We wished to examine the effects of plasmotype diversity on growth and productivity of barley grown under ambient vs high temperatures and test possible relationship between circadian clock and growth plasticity. Previously, we described the generation of the ASHER doubled haploid population from two reciprocal hybrids between Ashkelon (B1K-09-07) and Hermon (B1K-50-04) wild barleys (Bdolach et al., 2019) This population of 121 genotypes is composed of 40 and 81 carriers of the B1K-09-07 and B1K-50-04 cytoplasms, respectively, whereby significant differences between two groups could be associated with plasmotype (mitochondria and chloroplast) variation. In addition to the homozygous ASHER population we developed an additional population by carrying out a set of reciprocal crosses between 11 wild barley accessions to achieve a full-diallel with few genotypes missing (see Methods). The rationale behind the diallel population is that any difference between pairs of hybrids can be associated with plasmotype differences between homozygous parental lines. Finally, we wanted to investigate the potential utility of the wild plasmotype for cultivated material and therefore generated and tested cytolines in the cultivar Noga background.

\section{Life history phenotypic responses in barley growing under high temperature}

The plants of both the ASHER and diallel populations were phenotyped for life history traits and tested for differences between ambient temperature (AT) and high temperature (HT) from beginning of tillering stage until grain filling. We found that most of the life history traits were significantly different between the two environments in both populations (Fig. 1a and 1b). In ASHER (Fig 1a), Days to flowering (DTF) was significantly lower under HT (69 \pm 4.3 days) as compared to AT (100 \pm 3.6 days) (Fig 1a). The reproductive traits were higher under AT vs HT conditions (avg spike dry weight $(\mathrm{ASDW})=0.89 \pm 0.13$ vs. $0.7 \pm 0.12 \mathrm{gr}$ and Spikes dry weight $(\mathrm{SpDW})=7.8 \pm 1.9$ vs $6.24 \pm 1.7 \mathrm{gr}$, respectively). Plant height (PH) at harvest was also higher under AT $(124.9 \pm 8.5 \mathrm{~cm})$ than under HT $(108.1 \pm 7.8 \mathrm{~cm})$ although vegetative dry weight (VDW) was lower under AT, i.e. $13.1 \pm 3.5$ gr vs $14.4 \pm 4.7$ gr in HT. As a result, Total dry matter (TDM) was not significantly different between environments (AT, $20.8 \pm 5.6$ and HT, $20.5 \pm 6$ gr). Spike length (SL) also was not significantly different between environments (AT, $9.7 \pm 0.9$ and HT, $9.7 \pm 1 \mathrm{~cm}$ ) while the variation in the number of spikes per plant (calculated as the coefficient of 
163 variation (CV), SLCV) is significantly lower (more stable) under AT (AT, $8.3 \pm 1.6$ 164 and HT, $11.03 \pm 4.2 \%$ ). This could also be viewed based on the wider distribution in 165 the SLCV under HT. It is interesting to note that while the HT affected the SpDW and 166 included in fact reproductive output loss, the VDW worked in an opposite manner 167 including gain in the weight of the non-reproductive parts under HT.

168 Unlike in the ASHER population, in the diallel experiment we noticed almost 169 identical DTF between HT and AT (DTF=-109.9 \pm 5.6 and $111.73 \pm 4.97$ days, 170 respectively) (Fig 1b). Similarly, unlike the significant effects of the thermal 171 environment on the vegetative traits, the reproductive traits were less affected. ASDW 172 is significantly yet mildly lower under AT $(0.93 \pm 0.24$ gr $)$ than under HT $(1.03 \pm 0.27$ 173 gr). For SpDW we could not detect a significant difference between environments 174 (7.13 \pm 2.2 and $7.35 \pm 3.16$ gr, respectively). PH is also not significantly different 175 between environments (104.06 $\pm 10.17 \mathrm{~cm}$ in AT and $104.04 \pm 12.05 \mathrm{~cm}$ in HT), as 176 compared to VDW and TDM that were significantly lower under AT (11.29 \pm 4 and $17718.5 \pm 5.5$ gr $)$ than HT $(16.38 \pm 6.8$ and $24.13 \pm 9.08$ gr $)$. SL and SLCV are 178 significantly lower under AT.

179 To summarize, in both field experiments of the two populations (ASHER and 180 diallel) the plants on average accumulated lesser VDW and showed higher stability 181 between spikes, i.e. lower VDW and SLCV, under AT. In addition, doubled haploid 182 plants were flowering earlier under HT.

183

\section{Plasmotype effects on plasticity of life history traits, circadian clock, and ChI F}

The ASHER population is composed of two sub populations, each carrying either the Ashkelon or Hermon plasmotypes (Bdolach et al., 2019). On average, carriers of the Hermon plasmotype flowered significantly earlier than the Ashkelon types under both HT and AT however, in both subpopulations, this manifested in the same acceleration of flowering by more than 2 days (Fig. 2a). For SL there is no difference (Fig 2b), but for the SLCV Hermon plasmotype is linked with lesser stability (Fridman, 2015), i.e. higher CV under HT (14.45\% under HT vs $8.8 \%$ under AT) as compared to Ashkelon (12.33\% under HT vs 9.32\% under AT) (Fig. 2c). Perhaps the most interesting comparison is between the total vegetative and reproductive outputs. The carriers of the Ashkelon plasmotype are on average very plastic for the plant biomass and for the derived total dry matter (Fig. 2d and 2e), while the Hermon plasmotype types are relatively stable for the biomass and respond 
197 significantly with reduction of the spikes dry weight under heat (Fig. 2f). This is in 198 comparison to the relative stable SpDW of the Ashkelon types (Fig. 2f).

199 The reciprocal nature of the hybrids in the full-diallel allowed us to group the 200 F1 plants into different plasmotype subpopulations and different male parent 201 subpopulations (representing the nucleotype). One-way ANOVA for each of these 202 two sub-populations indicated larger percentage variation explained (PVE) by the 203 nucleotype (male donors), in comparison to differences between plasmotype (female 204 donors) for few traits (Table 1). For example, for the ASDW under HT (PVE=41\% 205 for nucleotype vs $\mathrm{PVE}=27 \%$ for plasmotype) and DTF under AT (PVE $=43 \%$ vs $206 \mathrm{PVE}=32 \%)$ and $\mathrm{HT}(\mathrm{PVE}=37 \%$ vs $28 \%$ ). For majority of the life history traits we 207 found higher variation that explained by the plasmotype than nucleotype under both 208 temperatures (AT and $\mathrm{HT}$ ): for $\mathrm{PH}, \mathrm{PVE}=39 \%$ vs $30 \%$ and $33 \%$ vs $21 \%$ under AT 209 and HT, respectively. This was true also for reproductive output, e.g SpDW which showed higher variance between plasmotypes in AT ( $\mathrm{PVE}=35 \%$ vs $21 \%$ ) and to a lesser extent under HT (PVE $=23 \%$ vs 19\% between plasmotype and nucleotype contributions).

We also included similar clock analysis to the hybrids of the diallel as we previously conducted for the ASHER population, i.e. under optimal (OT) and high temperatures (HT) environments using SensPAM (See Methods; Bdolach et al., 2019). The clock rhythmicity (amplitude and period) is based on NPQlss measurements for three days under constant light (Dakhiya et al., 2017) ( . The clock amplitude was significantly higher under HT $(0.03 \pm 0.01)$ compared to OT $(0.015$ \pm 0.006 ) (Fig 3a). Regarding the clock period, we observed significantly higher values under OT $(24.9 \pm 2.6 \mathrm{~h})$ in comparison to HT $(23.3 \pm 1.9 \mathrm{~h}$; Fig $3 \mathrm{~b})$. This clock plasticity is similar to the one described for the ASHER population (Bdolach et al., 222 2019) with acceleration of the rhythmicity under higher temperatures. Fv/Fm is significantly higher under HT $(0.93 \pm 0.01)$ in comparison to OT $(0.92 \pm 0.01$; Fig $3 \mathrm{c})$ and significantly different for Fv/Fmlss $(0.9 \pm 0.01$ in OT vs $0.91 \pm 0.01$ in HT; Fig 3d). NPQlss and Rfd are significantly different under OT in comparison to HT (NPQlss $0.66 \pm 0.1$ vs $0.43 \pm 0.08$ and Rfd $1.6 \pm 0.2$ vs $1.18 \pm 0.18$; Fig 3e and f).

227 Overall, these F results suggest that under HT. photosynthesis is more efficient.

Differences between the contributions of plasmotype and nucleotype to clock 229 traits in the diallel are also found (Table 1), but to a lesser extent than for fitness traits. 230 This includes higher PVE by the plasmotype of $34 \%$ compared to $22 \%$ by nucleotype 
231 for period under HT. Similarly, the delta amplitude variation between hybrids is better

232 explained by plasmotype (32\%) compared to nucleotype (24\%) (Table 1).

233

234

Relationship between plasmotype and nuclear diversity and pleiotropic effects on

236

237 circadian clock and life history traits

In the diallel population we tested if there are reciprocal hybrids that significantly differ for life history and SensyPAM traits (Fig 4). We clustered phenotype measured in the nethouse as growth or reproductive ones and traits measured with SensyPAM as clock or Chl F parameters. The percentage of differing pairs of reciprocal hybrids is the highest for Fv/Fm under OT (44.8\%) and the lowest is zero hybrids for the difference of DTF under AT. If comparing the traits according to our clustering, we could see that the mean number of differing reciprocal hybrids is highest for Chl F (26.3\%), and second for clock traits (15\%), while growth and reproductive traits are falling behind with $5.23 \%$ and $3.73 \%$, respectively.

One direct attempt to test for the relationship between circadian clock behavior under OT and HT to that of the plants fitness in the field is to perform simple linear regression between the different traits (Table S1). We found the highest positive clock-fitness correlations exist between period under HT and the two time points of tiller height measurements at the tillering stage and the rate between them $(r=0.432$ and 0.535$)$. Period under HT is also positively correlated to ASDW and SL under AT $(\mathrm{r}=0.46$ and 0.42 , respectively). This suggests that faster growth under both AT and HT is connected to longer clock periods under HT. Negative correlation was found between thermal responses of the amplitude (delta amplitude (dAMP) between HT and AT) and DTF under AT and HT (r= -0.44 and -0.5$)$, i.e. the greater the value for dAMP, the earlier plants reach flowering. We also identified highly positive correlation between dAMP and SpDW under AT $(r=0.45)$. Finally, we found negative correlations between Fv/Fm and Fv/Fmlss under both OT and HT and PH under AT and HT and a smaller positive correlation with NPQlss.

Another way to look into the relationship between clock and growth traits is 261 through pleiotropy (same locus affecting several traits; (Chen and Lübberstedt, 262 2010)). We previously obtained circadian clock phenotypes and used this data for a 263 genome scan in the ASHER DH population. This allowed us to identify several QTLs 264 linked with variation in amplitude, period and heat responses (delta of the traits) and 
265 to verify them by segregation analysis (Bdolach et al. 2019). Here, we performed a 266 similar genome scan analysis with the new set of field phenotypes (see Methods), and 267 we also tested genetic models that include plasmotype and nuclear QTL interactions 268 (cytonuclear, or GxG interactions). The genome scan identified several major QTL 269 that are associated with the different traits, including few that we found to be 270 pleiotropic (Fig 5a). On chromosome 2 we found several significant QTLs for SDW 271 under HT (LOD=3.04), for VDW under HT and QxE (LOD= 8.86 and 8.68, 272 respectively). In addition, we positioned a major QTL for PH under HT (LOD=6.35) 273 which resides at the coordinates as the frp2.1 locus that we linked previously with 274 circadian clock period plasticity in the same population (Bdoalch et al., 2019). This 275 major pleiotropic QTL resides between positions 698,875,542 and 702,308,910 276 (Morex v1). In the previous work, we identified this locus based on a threshold model, 277 where we translated the period plasticity phenotype of the DH lines into a binary 278 vector. For PH, there was no significant difference between carriers of the two alleles 279 under AT, but under HT the Ashkelon allele was associated with a significant higher $280 \mathrm{PH}$ than the Hermon allele (114.65 $\mathrm{cm}$ vs $108.53 \mathrm{~cm}$, respectively) (Fig 5b). In 281 addition, carriers of the Ashkelon allele had on average a significantly higher VDW 282 under HT vs. AT (24.57 gr and $19.93 \mathrm{gr}$, respectively), which is significantly higher 283 than the results obtained for Hermon allele carriers under both treatments (14.86 gr in 284 AT and 16.01 gr in HT). VDW also showed a significant QxE interaction explaining $28550 \%$ of the trait variation (Fig. 5c). Another mild pleiotropic QTL is amp7.1 286 individually found for Amplitude under HT and QxE on chromosome 7 (498,472,330287 510,903,725; Morex v1). In this study we found this QTL for SL under HT (LOD= 288 8.47) (Fig 5a). For this QTL, SL of the Hermon allele carriers is higher in both 289 treatments than those DH carrying the Ashkelon allele (10.4 and $10.34 \mathrm{~cm}$ vs 9.66 and 2909.5 , respectively) (Fig 5d).

291 Finally, we tested the possible interactions between plasmotype and nuclear 292 QTLs, i.e. whether the plasmotype diversity is conditioning the effects of the nuclear 293 QTL. Under AT, for both VDW and SpDW the effect of the frp2.1 QTL on Ashkelon 294 vs. Hermon phenotypes was severely dependent on the DH plant carrying the 295 Ashkelon plasmotype (Fig. 6a and 6c). This epistatic effect of the plasmotype over the 296 nuclear locus was also found for VDW under HT (Fig. 6a) but did not appear when 297 looking at the reproductive output under HT (Fig. 6d). Superimposing a reaction norm 298 onto the interaction plot (Fig. 6b-d) indicates that recombination between the two loci 
299 (plasmotype and frp2.1) leads to an opposite behavior for the reproductive output.

300 While no significant changes were observed between the slopes of the different 301 plasmotype-frp2.1 combinations for AT and HT, the carriers of the Hermon 302 plasmotype with the Ashkelon allele at frp2.1 showed increased reproductive output 303 under HT compared to AT, in an opposite manner to the combination of Hermon304 Hermon in both nuclear and cytoplasmatic loci (Fig. 6f).

305 Additional significant cytonuclear interactions for a pleiotropic QTL, on clock 306 and growth, was found for amp7.1 and its combined effects on days to flowering. In 307 this amp7.1-plasmotype combination, we observed significant cross-over effects 308 (Malosetti et al., 2013), i.e. changes in the order of the amp7.1 genotypes between the 309 two different plasmotypes (figure 2). However, in this combination, the reaction norms looked identical between the four cytonuclear combinations.

\section{Plasmotype variation in Cytolines in clock rhythmicity, Chl F and life history traits}

To test the hypothesis that the plasmotype has a role in regulating phenotypic diversity and could be utilized for breeding heat tolerance, we backcrossed several wild barley accessions with a cultivated elite line while keeping the wild plasmotype, in order to obtain nearly-isogenic cytolines (see Methods). The cytolines were tested in the SensyPAM under OT and HT for clock rhythmicity (measured from NPQlss) and Chl F, and in the nethouse for life history traits under AT and HT (Fig S1c). We calculated delta values between HT to OT or AT, in SensyPAM as well as in the nethouse, for each trait as a measure of the thermal plasticity (Fig. 7). We found significant differences between cytolines for clock period under HT $(\mathrm{P}=0.004)$ and not

322 under OT ( $\mathrm{P}=0.17)$ (Fig S3a). Notably, the single cytoline that decelerated the clock 323 significantly between OT and HT is the one carrying the B1K-03 plasmotype (Noga ${ }^{03}$, 324 decelerated by $4.3 \mathrm{~h}, \mathrm{P}<0.05$; Fig $7 \mathrm{a})$. Unlike the relative uniformity between cytolines 325 for period under OT and HT (Fig. S3a) the variance between cytolines for clock 326 amplitude was significant under both OT $(\mathrm{P}=0.0001)$ and HT $(\mathrm{P}=0.006)$ (Figure $\mathrm{S} 3 \mathrm{~b})$.

327 Most of the cytolines showed a significant delta except $\operatorname{Noga}^{249}$ (Fig 7b). Similar to 328 the calculated amplitude (based on NPQlss rhythmicity) the physiological traits of Chl $329 \mathrm{~F}$ are significantly influenced by the plasmotype diversity both under OT $(\mathrm{P}=0.0002$ 330 and $\mathrm{P}<0.0001)$ and HT $(\mathrm{P}<0.0001)$ (Fig S3c and $\mathrm{d}$ ) and all cytolines show high 331 thermal plasticity (Fig 7c and d). 
332

333

334

335

336

337

338

339

340

341

342

343

344

345

346

347

348

349

350

351

352

353

354

355

356

357

358

359

360

361

362

363

364

365

We tested cytolines also in nethouse under AT and HT conditions. Differences between cytolines for DTF were significant only under HT (average of $117 \pm 17.4$ days) including a delay in flowering and no difference was detected under AT (average of $107 \pm 7.8$ days). The difference in DTF between cytolinesis significant under AT $(\mathrm{P}<0.0001)$, but no significant difference under HT, presumably since less plants were involved and not all the cytolines reached the flowering stage due to extreme temperatures observed during the year 2021 (Fig. S1). Plants were significantly higher under AT ( $\mathrm{PH}=105.6 \pm 10.4 \mathrm{~cm})$ compared to HT $(72.2 \pm 12.6 \mathrm{~cm})$ with all cytolines showing a significant plasticity (Fig 7f). Nevertheless, in both AT and HT treatments the cytolines were not significantly different for PH, SPP, SpDW, VDW and SL (Tukey-Kramer test; $\mathrm{P}<0.05$ ) (Fig S4b to ). There was no significant difference for Spikes per plant (SPP) between AT (13.64 \pm 5.4$)$ and HT (12.1 \pm 5.9$)$ and no significant delta (Fig. $7 \mathrm{~g}$ ). Cytolines $\mathrm{Noga}^{09}$ and $\mathrm{Noga}^{249}$ are more similar to Noga as compared to delta small difference indeed observed among other lines between treatments. There was a significant reduction in the SpDW between AT (16.7 $\pm 7.5 \mathrm{gr})$ and HT ( $9 \pm 6.3 \mathrm{gr})$ (Fig S4d), depicting the heat's clear detrimental effects on reproductive fitness. There is a large difference in SpDW-related delta values between the three cytolines $\mathrm{Noga}^{02}$, Noga ${ }^{03}$, and Noga ${ }^{386}$, andNoga (Fig 7h). VDW is significantly different between AT (21.16 gr) and HT (17.8 gr) and the delta values for $\mathrm{Noga}^{09}$ and $\mathrm{Noga}^{249}$ differ a lot from the values observed for Noga. VDW shows a highly significant decrease between AT (21.2 \pm 8.2 gr $)$ and HT (18.1 \pm 7.1 gr $)$ and high variance exists between cytolines regarding their delta values. However, only Noga ${ }^{249}$ differs in delta from Noga. SL also changes significantly between AT $(11.2 \pm 1.3 \mathrm{~cm})$ and HT $(9.1 \pm 1.9 \mathrm{~cm})$, and there is high variance between the cytolines, Noga ${ }^{249}$, $\mathrm{Noga}^{29}, \mathrm{Noga}^{386}$ and Noga ${ }^{50}$ cytolines being significantly different in delta from Noga (Fig. 7j).

\section{Candidate chloroplast diversity underlying traits variation}

In our previous study (Bdolach et al., 2019) we obtained and compared the chloroplast sequences of B1K-09-07 and B1K-50-04, which represent the parental lines of the ASHER doubled haploid population. Here, we expanded the collection of wild barley chloroplast sequences and included nine additional accessions (see Methods), in an attempt to associate the variation in clock and life history traits observed in the diallel to organelle genome diversity. Since our diallel doesn't meet 
366 the population size criteria necessary for GWAS, we performed a Student's t-Test for 367 each clp haplotype with the different traits and corrected for the multiple testing 368 (number of haplotypes; see Methods). Sequence alignments of the 11 chloroplast 369 genomes identified 11 distinct haplotypes which include one to three genes (Table 370 S2). Overall, we could observe that among the diallel hybrids, clp haplotypes are 371 more significantly associated with variation in reproductive, compared to other trait 372 types. (Fig 8). Previously, the comparison between Ashkelon and Hermon's 373 chloroplast genomes (B1K-09-07 and B1K-50-04) identified a non-synonymous SNP 374 at the rpoC1 gene (position: 24553; N571K) and we speculate that this gene could be 375 responsible for the clock difference between the two subpopulations within ASHER 376 (Bdolach et al., 2019). In the current diallel, the rpoC1 and matK (position: 2099) co377 segregate and this matK/rpoCl haplotype is significantly associated with DTF under 378 AT and HT $(\mathrm{P}<0.0001)$ but not with the clock traits. However, another member of the 379 PEP complex (Hess et al., 1993; Gajecka et al., 2021), i.e. rpoC2, appeared as a 380 significant QTLs for several growth and reproductive traits. Within rpoC2 we 381 identified four SNPs (positions: 26445, 26808, 28702 and 29415) with the first two 382 SNPs being in full linkage disequilibrium (LD), i.e. they are co-segregating between 383 lines. The third and fourth rpoC2 SNPs are each in LD as well, either with $n d h C$ 384 (position: 49896) or with atpl (31364) and rps3 (80078). Within the diallel, the first 385 rpoC2 haplotype (namely rpoC2) is significantly associated with ASDW under both 386 AT and HT for $(\mathrm{p}<0.0003$ and 0.003 , respectively), DTF $(\mathrm{p}<0.0007$ and 0.0012 , 387 respectively), SL (0.0009 and 0.0004, respectively) and VDW (0.0014 and 0.0004, 388 respectively) and only under AT it is associated with TDM $(\mathrm{p}<0.0012)$. The second 389 haplotype, $r p o C 2 / n d h C$, is only significant for SL under AT (0.0004). The $390 \mathrm{rpoC2} / \mathrm{atpl} / \mathrm{rps} 3$ haplotype is also significant under both AT and HT for SpDW $391(\mathrm{p}<0.0001$ and 0.0022), TDM $(\mathrm{p}<0.0001$ and 0.0015) and VDW $(\mathrm{p}<0.0017$ and 392 0.0049). This $r p o C 2 / a t p l / r p s 3$ haplotype is significant $(\mathrm{p}<0.005)$ for the clock trait 393 dAmplitude. In $a t p B$ we identified two SNPs (positions: 52210 and 52297). For cemA 394 and $n d h F$, and for pet $B$, there was no significant association to any of the phenotypes. 395 We identified $\inf A$ and $n d h D$ haplotypes as a significant QTLs $(\mathrm{p}<0.0053)$ for 396 NPQlss under HT. To summarize, in this diallel analysis we identified more diversity 397 linked with reproductive traits, e.g DTF, than for clock traits. Nevertheless, significant 398 association between the rpoB/rpoC2/atp haplotype and clock amplitude plasticity 399 (delta Amp) could be observed. 
bioRxiv preprint doi: https://doi.org/10.1101/2021.11.02.466976; this version posted November 2, 2021. The copyright holder for this preprint (which was not certified by peer review) is the author/funder, who has granted bioRxiv a license to display the preprint in perpetuity. It is made available under aCC-BY-NC-ND 4.0 International license.

400

401

402

403

404 
405

406

407

408

409

410

411

412

413

414

415

416

417

418

419

420

421

422

423

424

425

426

427

428

429

430

431

432

433

434

435

436

437

438

\section{DISCUSSION}

Whole plant and circadian clock responses to high temperatures and their interrelationship vs pleiotropy

In this study we found significant responses of plant growth and clock rhythmicity under elevated temperature. Comparison between early and late growth phenotypes showed that plants growing in high temperatures initially gain some growth advantage, as reflected by the higher tiller heights measured at about one month after transplanting. However, at the final time of harvest the heat is correlated significantly with reduced height, biomass and reproductive output (Fig. 1). Also, we found that heat is related with loss of robustness of the growth as could be viewed in the significant elevated $\mathrm{CV}$ of the spikes. Interestingly, the population of inbreds (ASHER DH) seemed to be more affected than the diallel hybrids, with the latter maintaining, for example, a similar mean for PH and SL values. These differences in the stability of hybrids was reported in many plant species and might be related with higher allelic heterogeneity across the genome (Fridman, 2015), which to some extent may allow the plant to show a wider reaction norm as suggested in biochemical models of heterosis (Goff, 2011).

Regarding the circadian clock output, which is measured at the early stages of development during the transition to flowering (leaf 3-4), the heat exerted a significant effect in both populations (ASHER (Bdolach et al., 2019) and diallel; Fig. 3 ), whereby the trends observed in the diallel are similar to those reported before for the DH population, with a mean acceleration of the clock by $1.97 \mathrm{hr}$ and reduction of the amplitude by $2.4 \%$. Although all traits were affected by the heat, the correlation matrix between them did not find many significant correlations between plasticity of clock and growth traits across either DH lines or hybrids. The link, however, could be established by pleiotropy at several loci such as frp2.1 or amp7.1 in the ASHER population, and with those QTLs CNI on the clock as well as vegetative and reproductive output of the plants (Fig. 6). Genetic correlations among traits arise from the pleiotropic effects of genes on multiple traits and/or linkage disequilibrium among distinct loci, each affecting a single member of the character complex (Flaconer and Mackay, 1996). The major differences between lack of relationship by genetic correlation (Table S1) to one found by pleiotropy (Fig. 6) are probably the additional genetic correlations with unmeasured traits (Gellman and Turner, 2020), or de facto 
439 inclusion of additional causal loci on either of the traits. For example, Vishnukiran et

440 al. (2020) report major pleiotropic QTLs in rice between straw nitrogen and yield

441 while there was no correlation between these two complex traits.

442

443

Nature of the plasmotype natural diversity contribute to phenotypic variance

444 The genetic association we performed between the DNA diversity found among the

445 wild barley in the ASHER or diallel population point to a significant effect of several

446 haplotypes on the pleiotropic effects of clock and life history traits (Fig. 6 and Fig.

447 S2). Previously, we reported on a non-synonymous variation in rpoC1 (N571K) as a

448 possible source for the significant differences in the clock plasticity between carriers

449 of the plasmotype of B1K-50-04 and B1K-09-07 (Bdolach et. al. 2009). The plastidial

450 rpoC1 protein is a subunit of the holo-PEP complex (plastid encoded polymerase)

451 known to interact with sigma factor 1-6, out of which at least SIG5 was shown to

452 regulate rhythms of gene transcription, e.g., psbD (Noordally et al., 2013). Moreover,

453 the PEP complex includes additional proteins encoded by chloroplast genes

454 (Pfannschmidt et al., 2015) for which we identified association with pleiotropic

455 effects on life history and clock traits (Fig. 8). This includes the link between diversity

456 at the rроC2 and $r p o B$ genes with the amplitude variation, mostly under HT.

457 Zooming in on this significant and hitherto unknown relationship between

458 PEP variation and clock thermal plasticity will require a more thorough analysis of

459 more advanced and isogenic lines. In the PEP complex, one major functional group is

460 comprised of PAPs involved in DNA/RNA metabolism and gene expression

461 regulation, while the second group is related to redox regulation and reactive oxygen

462 species protection (Steiner et al., 2011). Moreover, the PEP is somehow coordinated

463 with the nuclear encoding RNA polymerase (Pfannschmidt et al., 2015). Therefore,

464 presumably non-synonymous variations (such as those between rpoC2 alleles in

465 current study) could be as effective as non-synonymous ones (between $\mathrm{rpoCl}$ alleles)

466 in the functionality and variation we observed. It would be therefore required to look

467 at different layers (transcriptome, proteome) between nearly isogenic and not

468 necessarily knockout mutant lines to achieve relevant causal variation. Recent

469 developments in plastid gene editing, also in cereals, may assist in generating and

470 analyzing both types of mutations in barley and learn how they might modulate

471 physiology and development of the plant under normal and high temperatures. Recent

472 experiments suggest that most recent developments of TALLEN-based allele editing 
473 tested in Arabidopsis (Nakazato et al., 2021) could also be applied in barley (Fridman

474 and Arimura, Personal communication) to allow such multi-layer analysis of isogenic 475 mutants.

476

477

478

479

480

481

482

483

484

485

486

487

488

489

490

491

492

493

494

495

496

497

498

499

500

501

502

503

504

505

\section{Candidate genes in the frp2.1 and amp7.1 loci}

We identified 48 and 71 high confidence genes in frp2.1 and amp7.1, respectively. In the Barley NET we identified 751 genes that are interacting with the core clock genes in barley with scores ranging between 16 (highest) to 1.12 (lowest; Table S3-6). Within the amp7.1 QTL region, we found four candidate genes including HORVU7Hr1G083270 (WRKY DNA-binding protein 70, score 1.89), HORVU7Hr1G083360 (NAD-dependent epimerase/dehydratase, score 1.42), HORVU7Hr1G084240 (transcription factor HY5, score 1.31), and HORVU7Hr1G084310 (overexpressor of cationic peroxidase 3, score 3.27). The guide (core circadian) genes for these interacting genes are PRR95 and PRR7 In Arabidopsis, the HY5 binds with the G-box element of the Lhcb promoters thus indicating that $C C A 1$ can alter HY5-binding to the G-box through a direct proteinprotein interaction in Lncb and CCAl (Andronis et al., 2008). Furthermore, the absence of HY5 leads to a shorter period of Lhcbl. This suggest that interaction of the HY5 and CCA1 proteins on Lhcb promoters is necessary for normal circadian expression of the $L h c b$ genes, which may be related to the F-based measurements in current study. Regarding the frp2.1 QTL region, we found only one candidate interactive locus i.e. HORVU2Hr1G103620 (ABC transporter C family member 2, Score- 1.87). Notably, mining the allelic diversity of these candidate genes within the larger Barley1K GWAS panel (Hubner et al., 2009) provides further support to their role in the manifestation of the rhythmicity of the clock output, and its plasticity under high temperature. For example, the frp2.1 region was also found in association with period under HT in the larger B1K panel (Manuscript in preparation).

It may well be that implementation of two-dimensional QTL studies in larger populations will validate the observed cytonuclear interactions (Fig. 6; Fig. S2) however, it will require a larger scale of Barley1K chloroplast sequencing. These in silico identified interactions between candidate loci can then be further verified in invivo interaction studies that would expand our knowledge of the circadian clock network and its role in heat sensing and plant responses. 
506

507

508

509

510

511

512

513

514

515

516

517

518

519

520

521

522

523

524

525

526

527

528

529

530

531

532

533

534

535

536

537

The potential of ancestor plasmotype and cytonuclear diversity for crop improvement

The potential of plasmotype diversity for breeding better adapted barley could be considered from the perspective of several important traits relevant to adaptation to different environments. Based on the reciprocal hybrids and cytolines, our results clearly show that flowering time is perhaps the trait most affected by plasmotype diversity. For example, the flowering of cytoline Noga ${ }^{03}$ under HT is not significantly delayed as compared to the cultivated Noga reference, which is flowering more than two weeks later under the same conditions (Fig. 7e). This robustness includes reduced effects of the heat on the reproductive output (Fig. 7h). While these plasmotype alleles bear the potential to increase crop fitness and broaden the environment in which we can grow a major crop plant, the cytonuclear interactions are as important to consider. The mutual conditioned effects of nucleotype and plasmotype QTL (Fig. 6) indicate that a more extensive genetic infrastructure is required to capture both types of wild alleles in a cultivated genetic background in order to allow field-testing. The current multi-parent populations in cereals and barley do not include cytonuclear interactions segregation (Schnaithmann et al., 2014; Maurer et al., 2015; Novakazi et al., 2020). Therefore, we recently developed a barley interspecific cytonuclear multi-parent population (CMPP) with the goal of studying CNI and its utility for breeding and for testing pleiotropic effects on clock rhythmicity and thermal plasticity.

\section{CONCLUSIONS}

The ability to test clock phenotypes on the same populations that grow in the field and identify the underlying genetics is key to understanding the relationships between important plant traits and circadian clock mechanisms. (here, and reviewed in Panter et al., 2019). The low occurrence of significant correlations between clock and fitness traits yet the existence of significant pleiotropic QTLs (Prusty et al., 2021) highlight the complex nature of circadian clock rhythmicity and yield traits. Several studies show the effect of clock gene mutants on crop behavior in natural and agricultural environments (Izawa et al., 2011; Bendix et al., 2015). Here, we show that accounting for plasmotype diversity, which modulates the plasticity of clock output, has the potential to confer yield robustness under adverse thermal conditions Pinpointing the underlying pleiotropic genes is a key to further unravelling the 
538 interplay between core and output clock pathways, which may work in both directions

539 through mechanisms yet to be discovered.

540

541

542

543

544

545

546

547

548

549

550

551

552

553

554

555

556

557

558

559

560

561

562

563

564

565

566

567

568

569

570

571

\section{MATERIALS AND METHODS}

Plant material

The source for the ASHER and diallel populations described in this study are barley accessions (Hordeum vulgare ssp. spontaneum) that we selected from the Barley1K collection in Israel to represent the different genetic clades (Hubner et al., 2009). In addition, few lines are from the IPK collection (Maurer et al., 2015). Included also in the diallel and as cultivated background for making cytolines is the $H$. vulgare cultivar cv. Noga which is the leading barley line in Israel. The wild accessions are from Yerucham (B1K-02-02), Michmoret (B1K-03-09), Ein Prat (B1K-04-04), Neomi (B1K-05-07), Ashqelon (B1K-09-07), Mount Arbel (B1K-29-13), Mount Harif (B1K-33-09), Jordan Canal (B1K-42-16), Mount Eitan (B1K-49-19), Mount Hermon (B1K-50-04), Kisalon, Israel (HID386), Turkey (HID357) and Iran (HID249). The ASHER is an F3 DH population generated from two reciprocal hybrids between Ashkelon (B1K-09-07) and Mount Hermon (B1K-50-04) and we described it in detail earlier (Bdolach et al., 2019b). The diallel is a reciprocal cross scheme between 11 wild accessions (from the B1K and HID386) and Noga that were intercrossed on each other to create a full set of hybrid pairs that differ in their plasmotypes. To generate the cytolines in the background of cultivar Noga we continued with the F1 hybrids that carry the wild plasmotypes and kept backcrossing it to Noga as male for several generations. As an example, $\mathrm{Noga}^{02}$ is a cytoline that carry the plasmotype of B1K-02-02 after we performed five backcrosses followed by three generations of selfing to achieve $\mathrm{BC}_{5} \mathrm{~S}_{3}$ line. More cytolines are Noga ${ }^{03}, \mathrm{BC}_{5} \mathrm{~S}_{2}$ of Noga x B1K-03-09 cross; Noga ${ }^{09}, \mathrm{BC}_{5} \mathrm{~S}_{2}$ of Noga x B1K-09-07 cross; Noga ${ }^{249}$, $\mathrm{BC}_{4} \mathrm{~S}_{2}$ of Noga x HID249 cross; Noga ${ }^{29}, \mathrm{BC}_{5} \mathrm{~S}_{3}$ of Noga x B1K-29-13 cross; Noga ${ }^{386}$, $\mathrm{BC}_{3} \mathrm{~S}_{2}$ of Noga x HID386 cross, and Noga ${ }^{50}, \mathrm{BC}_{3} \mathrm{~S}_{2}$ of Noga $\mathrm{x}$ B1K-50-04 cross.

\section{Growth and phenotyping.}

We conducted the net house experiments in the Agricultural Research Organization Volcani (ARO) Center, Israel. We sowed the different lines in germination trays and at the 3-leaf stage transplanted the seedlings in randomized block design into troughs measuring $0.4 \times 0.3 \mathrm{~m}$ (Mapal Horticulture Trough System, Merom Golan, Israel). A 
572 trough contained two rows of plants and the soil was composed of two layers of

573 volcanic soil (4-20 type of rough soil topped by a finer Odem193 type; Toof Merom

574 Golan, Merom Golan, Israel). We applied irrigation and fertilization using a drip

575 system (2L per hour, every $30 \mathrm{~cm}$ ) four times a day for 10 minutes. Due to the

576 sensitivity of wild barley to day-length conditions, we preferred to achieve mild

577 higher temperature conditions by warming the nethouse rather than late sowing

578 conducted for example for tomato (Bineau et al., 2021). We achieved high

579 temperature treatment (HT) by covering half of the insect-proof with nylons and

580 heating with electric heathers (3KW; Galon fans and pumps Ltd, Nehora, Israel). The

581 second half of the nethouse remained with only net walls and ventilated with a large

582 fan to take out the hot air for the ambient temperature treatment (AT). The thermal

583 differences between HT and AT is depicted in fig. S1, with a mean increase of $3.9^{\circ} \mathrm{C}$

584 and $2.8^{\circ} \mathrm{C}$ during day and night time and maximum delta of mean $7.5^{\circ} \mathrm{C}$ between AT

585 to HT.

586 We measured circadian clock amplitude and period in high-throughput

587 SensyPAM (SensyTIV, Aviel, Israel) custom-designed to allow Fluorescence

588 measurements (Bdolach et al., 2019) under optimal temperature of $22^{\circ} \mathrm{C}$ (OT) or high

589 temperature of $32^{\circ} \mathrm{C}(\mathrm{HT})$. We calculated the Fluorescence parameters NPQlss,

$590 \mathrm{Fv} / \mathrm{Fm}, \mathrm{Fv} / \mathrm{Fmlss}$ and $\mathrm{Rfd}$ as average of all three days measurements under continuous

591 light (Dakhiya et al., 2017). We calculated the period and amplitude of the circadian

592 clock output using the BioDare platform (https://biodare2.ed.ac.uk) (Zielinski et al., 593 2014).

594 We obtained the life history traits phenotype for the ASHER population lines 595 during winter of 2017-2018 in six replicates per treatment. The reciprocal diallel 596 population were grown during winter of 2019-2020 and the cytolines experiment was 597 conducted in winter of 2020-2021. We began phenotyping by measuring Tiller height $598(\mathrm{TH})$, that is the length of the longest tiller from ground level to the last fully 599 expended leaf in that tiller. Tiller number (TN) is the number of tillers per plant and it 600 was determined about one month after transplanting the plants. TH and TN ware 601 measured once (_1) or twice ( 2 ) with 14 days apart. We calculated TH rate by 602 suspecting TH_2 with TH_1 and dividing with the number of days between these two 603 measurements. We determined the number of days to flowering (DTF) based on the 604 date when the first awns appear in the main tiller. During grain filling we measured 605 five spikes per plant for spike length (SL) and later to obtain SLCV. In addition, 
606 during grain filling we measured plant height $(\mathrm{PH})$ from ground to the start of the

607 toolset spike. We then cached the five and whole spikes of each plant in separate 608 paper and nylon bags, respectively. Plants ware left to dry for several weeks after 609 irrigation was terminated. We harvested dry plants by cutting at soil level and placing 610 them in the nylon bags. Weight of the nylon bag with the plant is the total dry matter 611 (TDM). We collected dispersal units from bag and weighted them. We calculated 612 average spike dry weight (ASDW) based on weighing the five spikes that we cached 613 in the paper bag. We then summed the weight of spikes (dispersal units) in the plastic 614 and paper bags to obtain spikes dry weight (SpDW). Vegetative dry weight (VDW) is 615 the reduction of SpDW from TDM. In the cytolines experiment, we also counted 616 Spikes per plant (SPP) and the ASDW based on those spikes.

617

618

619

620

621

622

623

624

625

626

627

628

629

630

631

632

633

634

635

636

637

\section{Genome-wide and cytonuclear interaction QTL analysis}

The description of the ASHER SNP genotyping and QTL analysis for the different traits is described in Bdolach et al., 2019. The genome-wide QTL interaction analysis of the DH population for different traits carried out using inclusive composite interval mapping (ICIM; (Li et al., 2007)) with the IciMapping V4.1 (Meng et al., 2015) software package. IciM 4.1 uses an improved algorithm of composite interval mapping for bi-parental population. The QTL by environment interaction (QxE) was also assessed with the inclusive composite interval mapping (ICIM) method, using the MET function of the software QTL IciMapping 4.1 (Li et al., 2007, Meng et al., 2015). Illumina paired-end libraries (375 bp insert size) of total barley DNA from mature leaves were used to sequence the plastid genomes of the parental lines as previously described (Bdolach et al., 2019).

\section{Statistical analysis}

The JMP version 14.0 statistical package (SAS Institute, Cary, NC, USA) was used for statistical analyses. Student's t-Tests between treatments, plasmotypes and alleles were conducted using the 'Fit $\mathrm{Y}$ by $\mathrm{X}$ ' function. A factorial model was employed for the analysis of variance (ANOVA, Fig. 6), using 'Fit model', with temperature treatment and allelic state as fixed effects.

Candidate genes in the frp 2.1 and amp7.1 
638 We downloaded the list of high confidence gene in the QTL intervals (frp2.1,

639 Chromosome 2:698,875,542-702,308,910; amp7.1, Chromosome 7: 498,472,330-

$640510,903,725)$ from BarleX database with Morex V1 annotation and tested them for

641 interaction with core clock gene in barley. For this, we retrieved the list of genes

642 involved in circadian pathway in Hordeum vulgare from plant reactome

643 (https://plantreactome.gramene.org). Plant reactome is the Gramene's pathway

644 knowledgebase that uses Oryza sativa as a reference species for manual curation of

645 the pathway and extends pathway knowledge for other 82 plant species via gene-

646 orthology projection (Naithani et al., 2020). BarleyNET inferred the co-functional

647 links between barley genes by analyzing various types of omics data obtained from

648 cultivated barley, as well as three other plant species (Arabidopsis thaliana, Zea mays,

649 and Oryza sativa) (Lee et al., 2020). In the BarleyNET, under the pathway centric

650 search function, the known circadian clock genes were used as the guide gene to

651 identify genes by 'guilt-by-association' method. These genes were prioritized by total

652 edge weight score (sum of log likelihood score) to the guide gene set.

653

654

655

656

657

658

659

660

661

662

663

664

665

666

\section{ACKNOWLEDGEMENTS}

We thank Dr Stephan Greiner (Max-Planck-Institut für Molekulare Pflanzenphysiologie, Golm, Germany) for sharing barley chloroplasts sequence data.

The authors are grateful to Royi Levav Oded Anner and Daniel Shamir (SensyTIV, Amiel, Israel) for their assistance in maintaining the SensyPAM as a system for measuring circadian rhythms. We also wish to thanks the technical assistance of laboratory member Avital Beery and Orit Amir-Segev.

\section{LIST OF AUTHOR CONTRIBUTIONS}

E.B and E.F. designed the experiments, collected, analyzed and interpreted data, and wrote the manuscript. E.B., M.R.P. K.K., and L.D.T were involved in the data analyses, their interpretation and in writing the manuscript. 
$\underline{\text { Table } 1}$

\begin{tabular}{|c|c|c|c|c|c|}
\hline Trait & Type & $\begin{array}{c}\text { male } \\
\text { parent } \\
\text { Prob > F }\end{array}$ & $\begin{array}{c}\text { male parent } \\
\text { PVE [\%] }\end{array}$ & $\begin{array}{c}\text { Plasmotype } \\
\text { Prob > F }\end{array}$ & $\begin{array}{c}\text { Plasmotype } \\
\text { PVE [\%] }\end{array}$ \\
\hline TH_1_AT & Growth & 0.0068 & $24 \%$ & $<.0001$ & $41 \%$ \\
\hline TH_1_HT & Growth & $<.0001$ & $37 \%$ & $<.0001$ & $36 \%$ \\
\hline TH_2_AT & Growth & $<.0001$ & $34 \%$ & $<.0001$ & $38 \%$ \\
\hline TH_2_HT & Growth & $<.0001$ & $36 \%$ & $<.0001$ & $46 \%$ \\
\hline TH rate_AT & Growth & $<.0001$ & $34 \%$ & 0.0002 & $32 \%$ \\
\hline TH rate_HT & Growth & $<.0001$ & $33 \%$ & $<.0001$ & $47 \%$ \\
\hline ASDW_AT & Reproductive & $<.0001$ & $43 \%$ & $<.0001$ & $35 \%$ \\
\hline ASDW_HT & Reproductive & $<.0001$ & $41 \%$ & 0.0037 & $27 \%$ \\
\hline DTF_AT & Reproductive & $<.0001$ & $43 \%$ & 0.0002 & $32 \%$ \\
\hline DTF_HT & Reproductive & $<.0001$ & $37 \%$ & 0.0008 & $28 \%$ \\
\hline$\overline{\mathrm{PH}} \overline{\mathrm{AT}}$ & Growth & 0.0007 & $30 \%$ & $<.0001$ & $39 \%$ \\
\hline $\mathrm{PH} \_\mathrm{HT}$ & Growth & 0.0266 & 21 & 0.0001 & $33 \%$ \\
\hline SL_AT & Reproductive & 0.0006 & $31 \%$ & $<.0001$ & $42 \%$ \\
\hline SL_HT & Reproductive & 0.0111 & $23 \%$ & 0.0007 & $30 \%$ \\
\hline SLCV_AT & Reproductive & 0.0215 & $22 \%$ & 0.0912 & $18 \%$ \\
\hline SLCV_HT & Reproductive & 0.2076 & $15 \%$ & 0.1434 & $16 \%$ \\
\hline TDM_AT & Reproductive & 0.0879 & $18 \%$ & $<.0001$ & $35 \%$ \\
\hline TDM_HT & Reproductive & 0.3174 & $13 \%$ & 0.0007 & $29 \%$ \\
\hline VDW_AT & Growth & 0.1108 & $17 \%$ & $<.0001$ & $35 \%$ \\
\hline VDW_HT & Growth & 0.1965 & $15 \%$ & 0.0003 & $31 \%$ \\
\hline SpDW_AT_AT & Reproductive & 0.028 & $21 \%$ & $<.0001$ & $35 \%$ \\
\hline SpDW_HT & Reproductive & 0.0566 & $19 \%$ & 0.0094 & $23 \%$ \\
\hline Amplitude_OT & Clock & 0.1819 & $24 \%$ & 0.1325 & $26 \%$ \\
\hline Amplitude_HT & Clock & 0.2046 & $23 \%$ & 0.136 & $26 \%$ \\
\hline Period_OT & Clock & 0.2694 & $22 \%$ & 0.387 & $19 \%$ \\
\hline Period_HT & Clock & 0.2715 & $22 \%$ & 0.0184 & $34 \%$ \\
\hline dAMP & Clock & 0.1892 & $24 \%$ & 0.0369 & $32 \%$ \\
\hline dPeriod & Clock & 0.7274 & $13 \%$ & 0.3768 & $20 \%$ \\
\hline Fv/Fm_OT & Chl F & 0.736 & $14 \%$ & 0.2647 & $23 \%$ \\
\hline Fv/Fm_HT & $\mathrm{Chl} \mathrm{F}$ & 0.4621 & $19 \%$ & 0.3934 & $20 \%$ \\
\hline Fv/Fmlss_OT & Chl F & 0.9231 & $09 \%$ & 0.0834 & $29 \%$ \\
\hline Fv/Fmlss_HT & Chl F & 0.8984 & $10 \%$ & 0.2307 & $24 \%$ \\
\hline NPQIss_OT & Chl F & 0.4743 & $18 \%$ & 0.0386 & $32 \%$ \\
\hline NPQIss_HT & Chl F & 0.1641 & $26 \%$ & 0.0551 & $31 \%$ \\
\hline Rfd_OT & Chl F & 0.1015 & $28 \%$ & 0.1697 & $25 \%$ \\
\hline Rfd_HT & Chl F & 0.0414 & $32 \%$ & 0.0327 & $33 \%$ \\
\hline
\end{tabular}

668

669

670

671 Figure 1: Mild increase in temperature has significant effect on plant

672 performance in the field. Distribution and box plot of life history traits under

673 ambient temperature (AT, black) and high temperature (HT, gray) (see Fig. S1 for 
674 differences between AT and HT) for a) ASHER DH population and b) full-diallel.

675 Life history traits include Tiller height at two time points and the rate between them,

676 Average Spike dry weight, Days to flowering (DTF), Spike length (SL), Spikes dry

677 weight (SpDW), Plant height (PH), Vegetative dry weight (VDW) and Total dry

678 matter (TDM). For each student's t-test between HT and AT, the p value is depicted

679 as *: $\mathrm{P}<0.05, * *: \mathrm{P}<0.01$ or $* * *: \mathrm{P}<0.001$

680

681 Figure 2: Thermal plasticity of life history traits is under cytoplasmic control in

682 wild barley. Reaction norms of life history traits depicting the average responses of 683 the two parental plasmotypes to mild heat. Differential response between the carriers 684 of Ashkelon (blue) and Hermon (red) plasmotype for a) Days to flowering (DTF), b) 685 Spike length (SL), c) Spike length CV (SLCV), d) Vegetative dry weight (VDW), e) 686 Total dry matter (TDM) and f) Spikes dry weight (SpDW). Levels not connected by 687 same letter are significantly different in student's t-test $(\mathrm{P}<0.05)$.

688

Table 1: One-way ANOVA for plasmotype vs nucleotype effects in the reciprocal 690 diallel population. Tiller height at two time points and the rate between them, Days 691 to flowering (DTF), Average Spike dry weight (ASDW), Plant height (PH), Spike 692 length (SL), spike length CV, Spikes dry weight (SpDW), Total dry matter (TDM) 693 and Vegetative dry weight (VDW) in the nethouse under ambient temperature (AT) 694 and high temperature (HT).

695 For clock and Chl F traits: Amplitude, Period, delta Amplitude (dAMP), delta Period 696 (dPeriod), Fv/Fm, F/Fmlss, NPQlss and Rfd in SensyPAN under optimal temperature 697 of $22^{\circ} \mathrm{C}(\mathrm{OT})$ or high temperature of $32^{\circ} \mathrm{C}(\mathrm{HT})$ and the delta HT-OT.

698

699 Figure 3: Chlorophyll florescence and circadian clock rhythmicity in barley 700 diallel grown under OT and HT. Distribution and box plot of clock output 701 rhythmicity: a) Amplitude, and b) Period, and for mean chlorophyll florescence traits: 702 , c) Fv/Fm, ( d) Fv/Fmlss, e) NPQlss and f) Rfd under optimal temperature (OT, 703 black) and high temperature (HT, gray) in the reciprocal diallel population. For each 704 student's t-test, the $\mathrm{p}$ value is depicted as *: $\mathrm{P}<0.05$, **: $\mathrm{P}<0.01$ or ***: $\mathrm{P}<0.001$. The 705 means of clock $\mathbf{g}$ ) period and $\mathbf{h}$ ) amplitude under optimal temperature (OT, black) and 706 high temperature (HT, gray) in SensyPAM for the H. spontaneum accessions parental 707 accessions of the diallel: B1K-02-02 (Yerucham), B1K-03-09 (Michmoret), B1K-04- 
708

709

710

711

712

713

714

715

716

717

718

719

720

721

722

723

724

725

726

727

728

729

730

731

732

733

734

735

736

737

738

739

740

741

04 (Ein Prat), B1K-05-07 (Neomi), B1K-09-07 (Ashqelon), B1K-29-13 (Mount Arbel), B1K-33-09 (Mount Harif), B1K-42-16 (Jordan Canal), B1K-49-19 (Mount Eitan), B1K-50-04 (Mount Hermon), HID386 (Kisalon, Israel) and the cultivar Noga.

\section{Figure 4: Proportion of crosses with significant difference between reciprocal} hybrids for phenotypic traits, under OT or AT and HT. Life history traits include: Tiller height $(\mathrm{TH})$ and number $(\mathrm{TN})$ at two time points and the rate between them, Days to flowering (DTF), Average Spike dry weight (ASDW), Plant height (PH), Spike length (SL), spike length CV (SLCV), Spikes dry weight (SpDW), Total dry matter (TDM) and Vegetative dry weight (VDW) for plants in the nethouse under ambient temperature (AT) and high temperature (HT). For clock and Chl F traits: Amplitude, Period, delta Amplitude (dAMP), delta Period (dPeriod), Fv/Fm, F/Fmlss, NPQlss and Rfd in SensyPAM under optimal temperature of $22^{\circ} \mathrm{C}$ (OT) or high temperature of $32^{\circ} \mathrm{C}(\mathrm{HT})$ and the delta HT-OT.

The mean for each type of traits is depicted: Growth or reproductive traits in the greenhouse experiment, and clock or Chl F in the SensyPAM.

Figure 5: Pleiotropic nucleotype QTL underlying life history traits plasticity. Circos plot depicting loci with significant effects under AT, HT and loci showing GxE interaction with thermal environment. a) Circus of LOD in the ASHER DH population for life history traits. From outer to inner lane: Days to flowering (DTF), Plant height (PH), Spike length (SL), Spikes dry weight (SpDW) and Vegetative dry weight (VDW) under ambient temperature (AT-yellow), high temperature (HT-red) and GxE (blue). Reaction norms of frp2.1 locus with pleiotropic effects on b) plant height (PH) and c) Vegetative dry weight (VDW), and of d) amp7.1 for spike length. Red and blue lines depict mean values of lines homozygous for the Hermon or Ashkelon alleles, respectively. Levels not connected by same letter are significantly different in student's t-test $(\mathrm{P}<0.05)$.

Figure 6: GxGxE interactions between plasmotype and frp2.1 nuclear QTL under ambient and high temperatures in ASHER DH population. Cytoplasm by nuclear (GxG) QTL interaction plots under a) ambient (AT) and b) high (HT) temperatures for vegetative DW. Similarly, interaction plots under c) ambient (AT) and d) high (HT) temperatures for spikes DW. Plasmotype is depicted in $\mathrm{x}$ axis 
742 (Ashkelon or Hermon), and red or blue lines illustrate the Hermon or Ashkelon alleles

743 in frp2.1. Reaction norms of the different Plasmotype-frp2.1 locus-combinations

744 between AT and HT for e) vegetative DW, and f) Spikes DW. Green, Ashkelon

745 (Plasmotype)-Hermon (frp2.1); Purple, Ashkelon-Ashkelon; Brown, Hermon-

746 Ashkelon; Orange, Hermon-Hermon.

747

Figure 7: Phenotypic variation and thermal plasticity of cytolines for clock

749 rhythmicity, Chl F, and life history traits. Bar plots for the delta between high 750 temperature $\left(\mathrm{HT}, 32^{\circ} \mathrm{C}\right)$ and optimal temperature $\left(\mathrm{OT}, 22^{\circ} \mathrm{C}\right)(\mathrm{HT}-\mathrm{OT} / \mathrm{AT})$ for

751 cytolines with wild barley plasmotype in the background of cultivated barley 752 phenotype. For clock traits in the SensyPAM under HT and OT: a) period, b), 753 amplitude, b) NPQlss, and d) Fv/Fm. For life history traits under AT and HT: e) days 754 to flowering (DTF), f) plant height (PH), g) spikes per plant (SPP), h) spikes dry 755 weight (SpDW), i) vegetative dry weight (VDW), j) and spike length (SL). The 756 Students's t test $\mathrm{p}$ value is depicted as *, $\mathrm{P}<0.05$; **, $\mathrm{P}<0.01$; or ***, $\mathrm{P}<0.001$.

Figure 8: Genetic association between chloroplast haplotypes (right) and 759 different clock and fitness traits (X-axis). Blue and red bars represent the $-\log _{10} \mathrm{P}$ 760 for Students's t test between haplogroups among the hybrids under OT/AT and HT, 761 respectively. The $-\log \mathrm{P}$ is calculated and corrected for multiple testing and the 762 threshold for $\mathrm{P}<0.05$ ( $-\log 10=2.3$ ) is indicated with horizontal orange line.

Table S1: Pearson correlations (r) between all phenotypic traits under optimal temperature $\left(\mathrm{OT}, 22^{\circ} \mathrm{C}\right)$ and high temperature $\left(\mathrm{HT}, 32^{\circ} \mathrm{C}\right)$ in the reciprocal dialle population.

Table S2: Chloroplast genes sequencing of the $H$. spontaneum accessions parental 771 accessions of the diallel: B1K-02-02 (Yerucham), B1K-03-09 (Michmoret), B1K-0477204 (Ein Prat), B1K-05-07 (Neomi), B1K-09-07 (Ashqelon), B1K-29-13 (Mount 773 Arbel), B1K-33-09 (Mount Harif), B1K-42-16 (Jordan Canal), B1K-49-19 (Mount 774 Eitan), B1K-50-04 (Mount Hermon), HID386 (Kisalon, Israel) and the cultivar Noga. 
776 Table S3: Barley circadian pathway genes from the plant reactome

777 (https://plantreactome.gramene.org)

778

779

780

781

782

783

784

785

786

787

788

789

790

791

792

793

794

795

796

797

798

799

800

801

802

803

804

805

806

807

808

809

810

Table S4: List of the interacting genes to the guide core circadian genes from BarleyNET pathway centric search

Table S5: High confidence candidate genes in amp7.1 chromosomal region

Table S6: High confidence candidate genes in frp2.1 chromosomal region

Figure S1: Mean daily temperature in the nethouse under ambient temperature (AT), high temperature (HT) and the delta between them (HT-AT). a) ASHER, b) diallel and c) cyolines experiments. Blue and orange lines represent the average day of flowering under AT and HT, respectively.

Figure S2: GxGxE interactions between amp7.1 and plasmotype under optimal and ambient temperatures. Cytoplasm by nuclear (GxG) QTL interaction plots under a) ambient (AT) and b) high (HT) temperatures for Days to flowering. Plasmotype is depicted in $\mathrm{X}$ axis (Ashkelon or Hermon), and red or blue lines illustrate the Hermon or Ashkelon alleles in amp7.1. Levels not connected by same letter are significantly different in student's t-test. c) Reaction norms of the different combinations Plasmotype-amp7.1 loci between optimal temperature (OT, $\left.22^{\circ} \mathrm{C}\right)$ and high temperature $\left(\mathrm{HT}, 32^{\circ} \mathrm{C}\right)$. Green, Ashkelon (Plasmotype)-Hermon (frp 2.1); Purple, Ashkelon-Ashkelon; Brown, Hermon-Ashkelon; Ornage, Hermon-Hermon

Figure S3: Clock rhythmicity and $\mathrm{Chl} F$ variation between cytolines under OT and HT. Cytolines with wild barley cytoplasm in the background of cultivated barley grown under optimal temperature $\left(\mathrm{OT}, 22^{\circ} \mathrm{C}\right)$ and high temperature $\left(\mathrm{HT}, 32^{\circ} \mathrm{C}\right)$. Bar plots with SE for the cytolines for a) period, b) amplitude, c) NPQlss and d) Fv/Fm. Different letters depict significant difference in a Tukey-Kramer test.

\section{Figure S4: No different between cytolines for life history traits under AT and}

HT. Cytolines with wild barley cytoplasm in the background of cultivated barley grown under ambient temperature (AT) and high temperature (HT). Bar plots and SE for a) days to flowering, b) plant height, c) spikes per plant, d) spikes dry weight, e) 
bioRxiv preprint doi: https://doi.org/10.1101/2021.11.02.466976; this version posted November 2, 2021. The copyright holder for this preprint (which was not certified by peer review) is the author/funder, who has granted bioRxiv a license to display the preprint in perpetuity. It is made available under aCC-BY-NC-ND 4.0 International license.

811 vegetative dry weight and f) spike length. Different letters depict significant

812 difference in Tukey-Kramer test.

813

814

815 
bioRxiv preprint doi: https://doi.org/10.1101/2021.11.02.466976; this version posted November 2, 2021. The copyright holder for this preprint (which was not certified by peer review) is the author/funder, who has granted bioRxiv a license to display the preprint in perpetuity. It is made available under aCC-BY-NC-ND 4.0 International license.

816

817 

a) ASHER
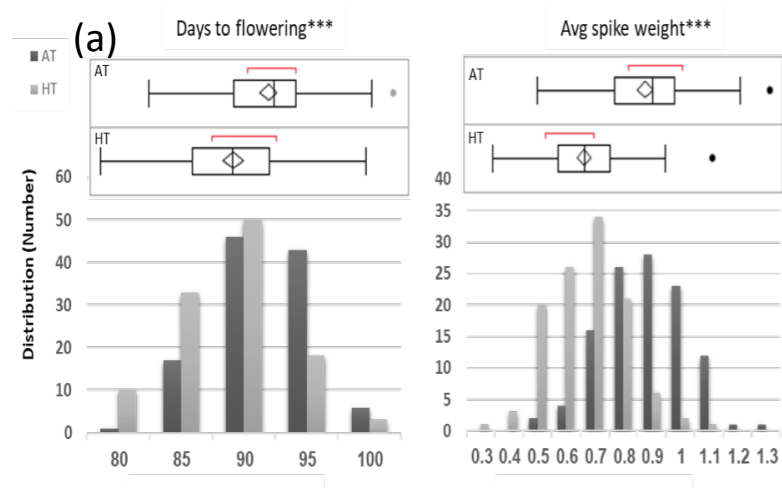

vegetative dry weigh

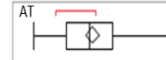

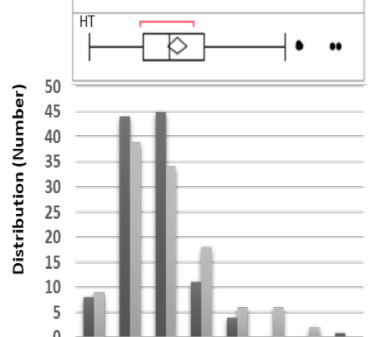

${ }_{40}$

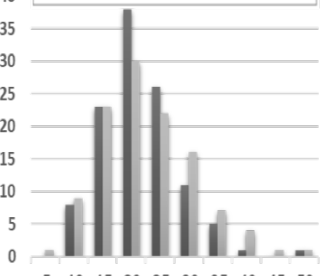

5101520253035404550
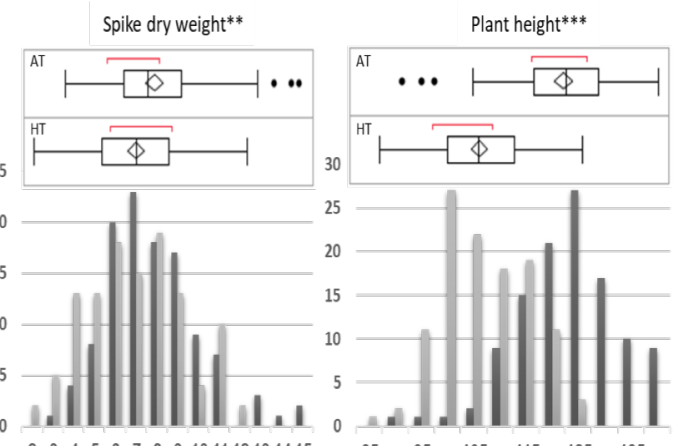

Spike length

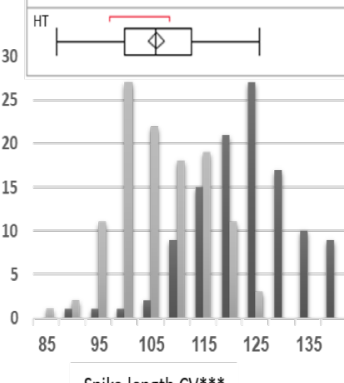

b) DIALLEL

(b)

年

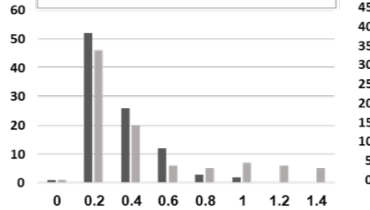

Avg spike weigh

Spike length $\mathrm{CV}^{* * *}$

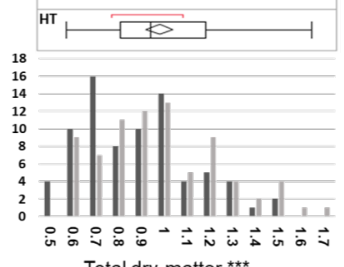

${ }^{A T} \vdash \bar{B}-\cdot \cdot$
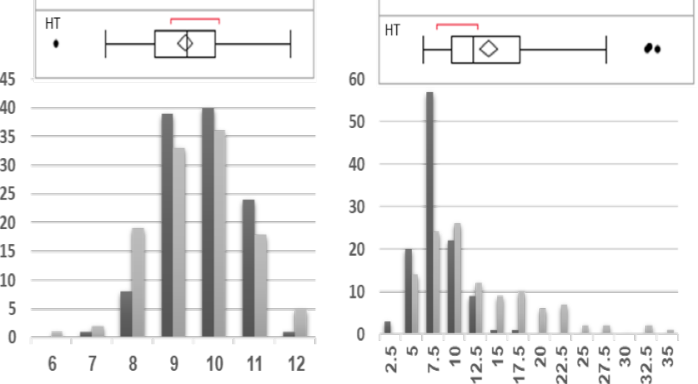

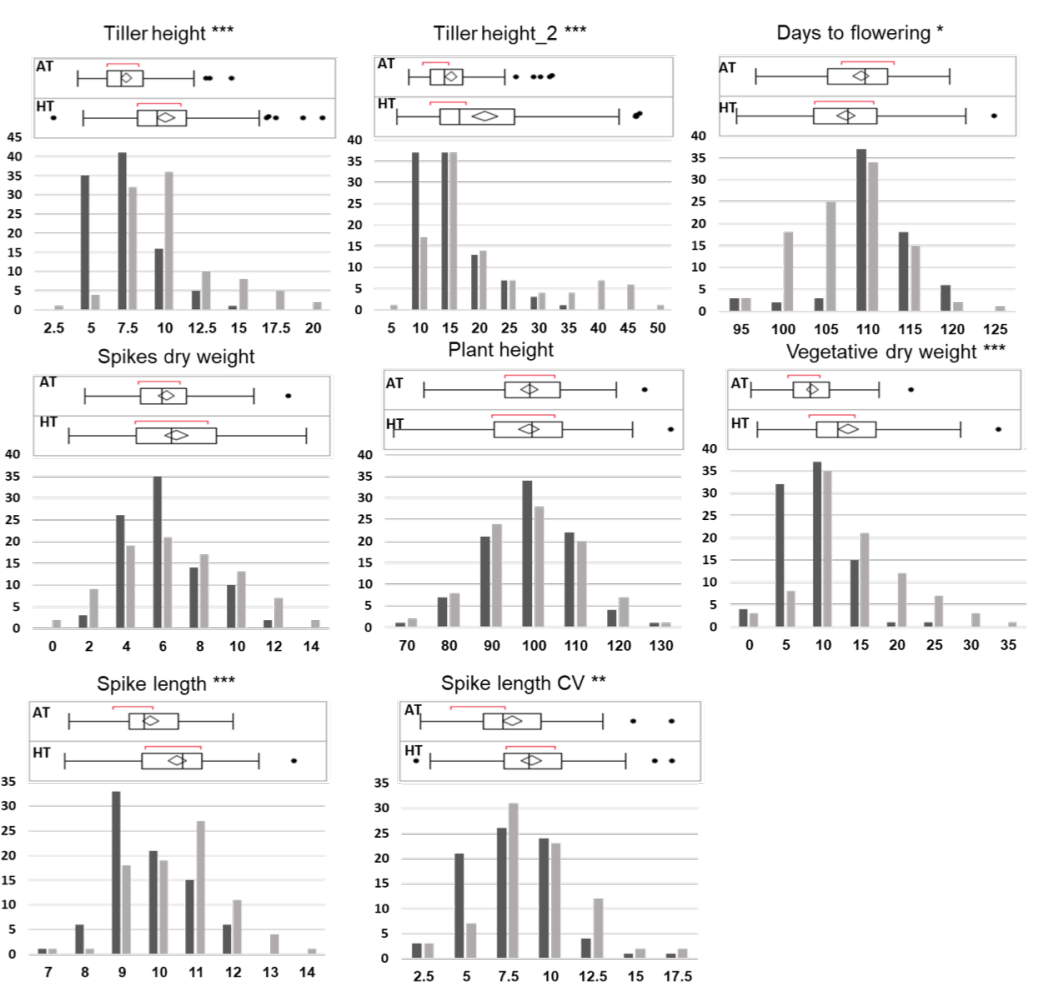

Figure 1 

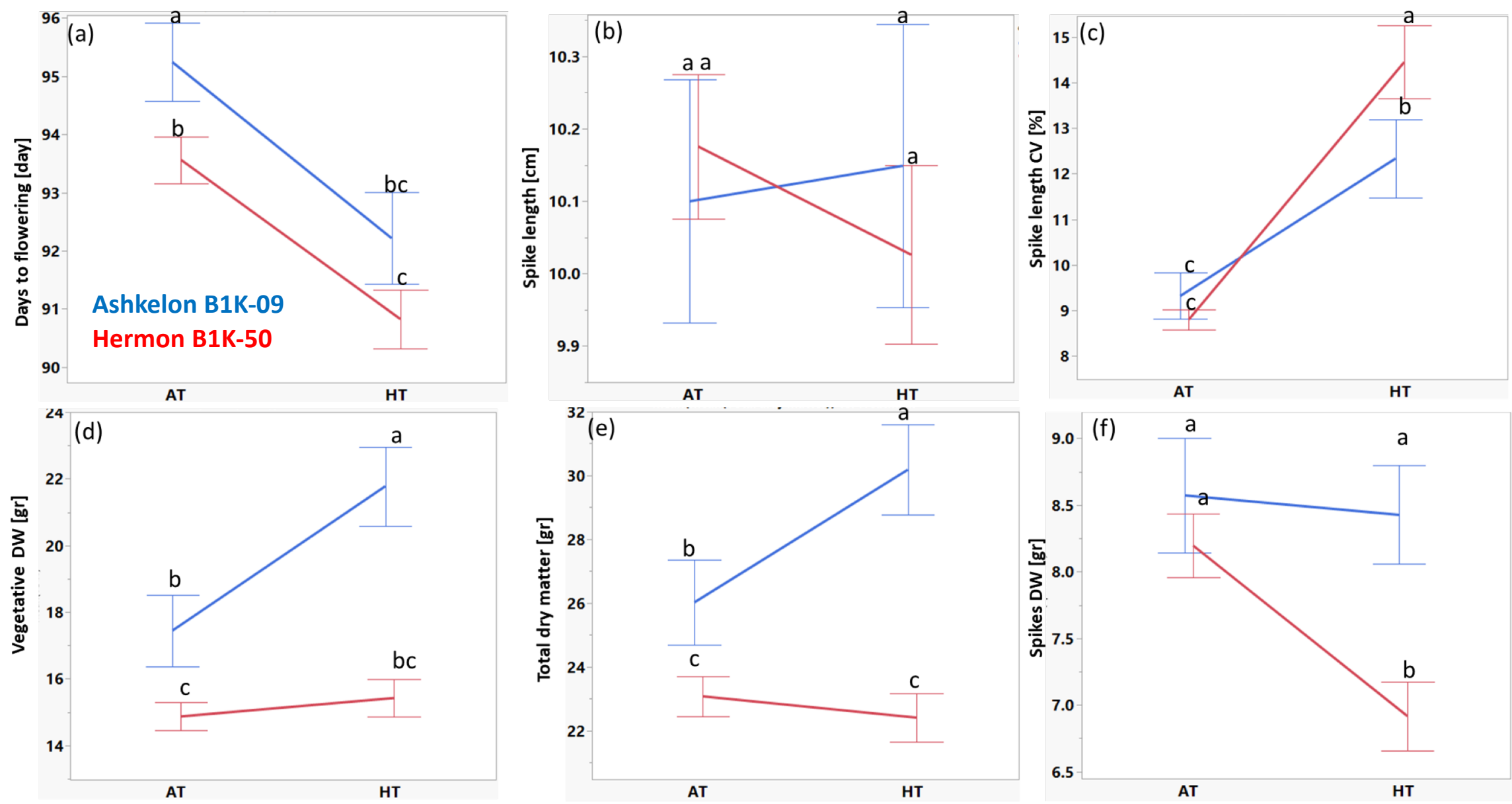

Figure 2 

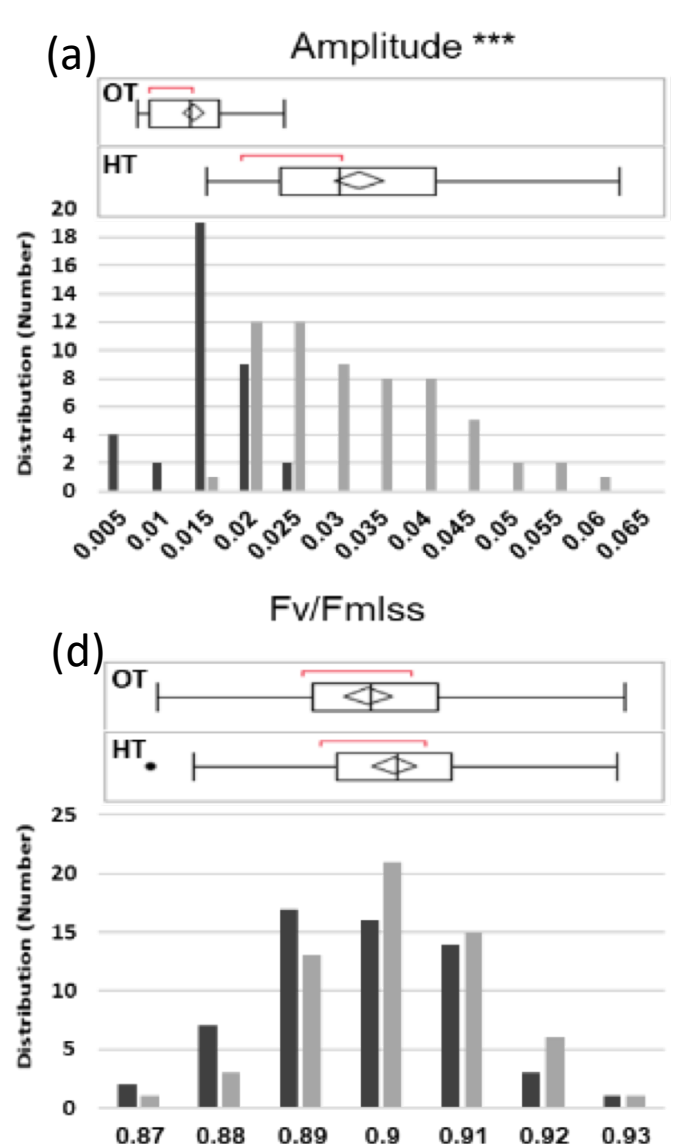
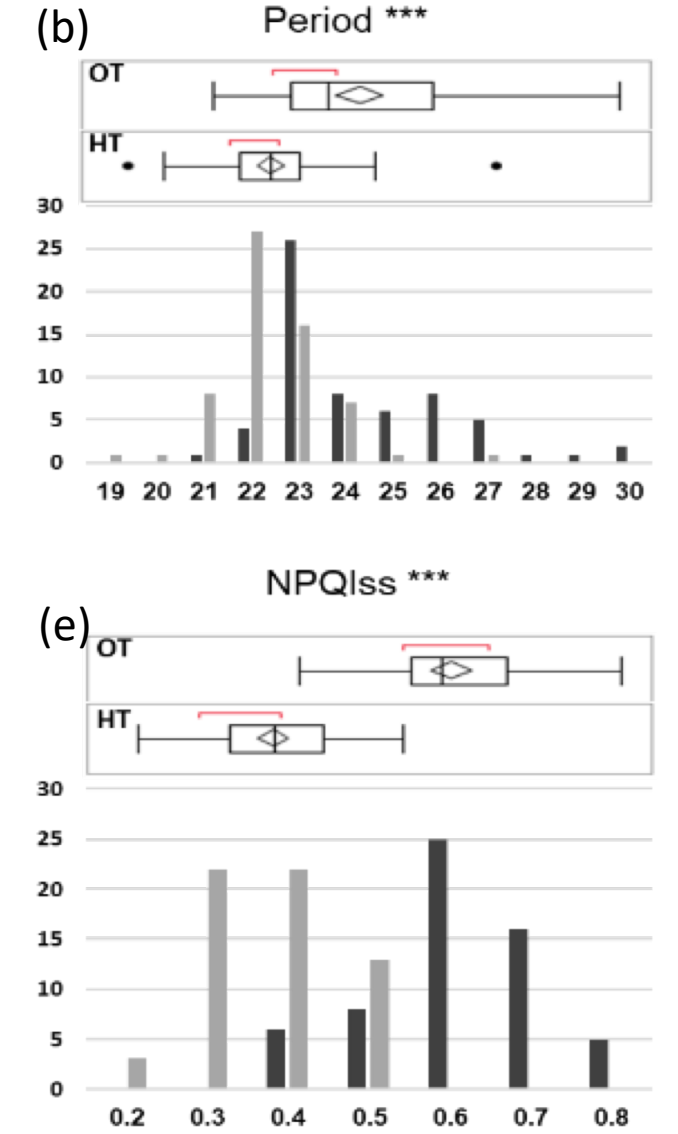
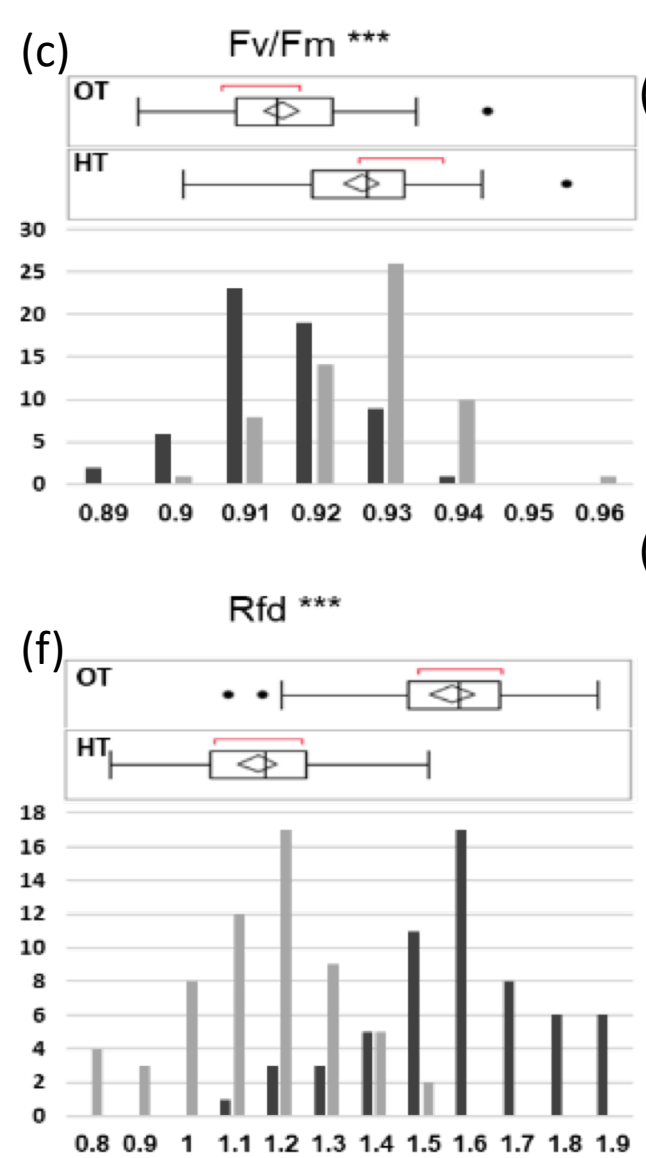

(g) 33

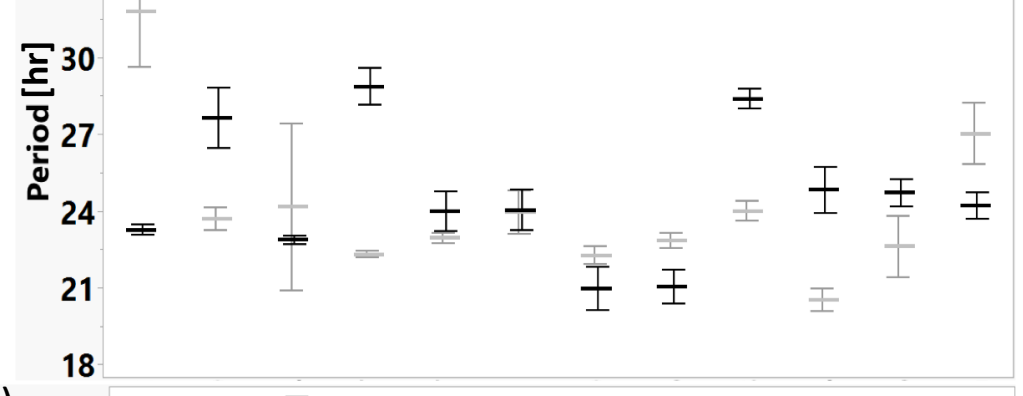

(h) 0.040

0.035

0.030

흠 0.020

है 0.015

0.010

0.005

0.000

Figure 3 
Chl F

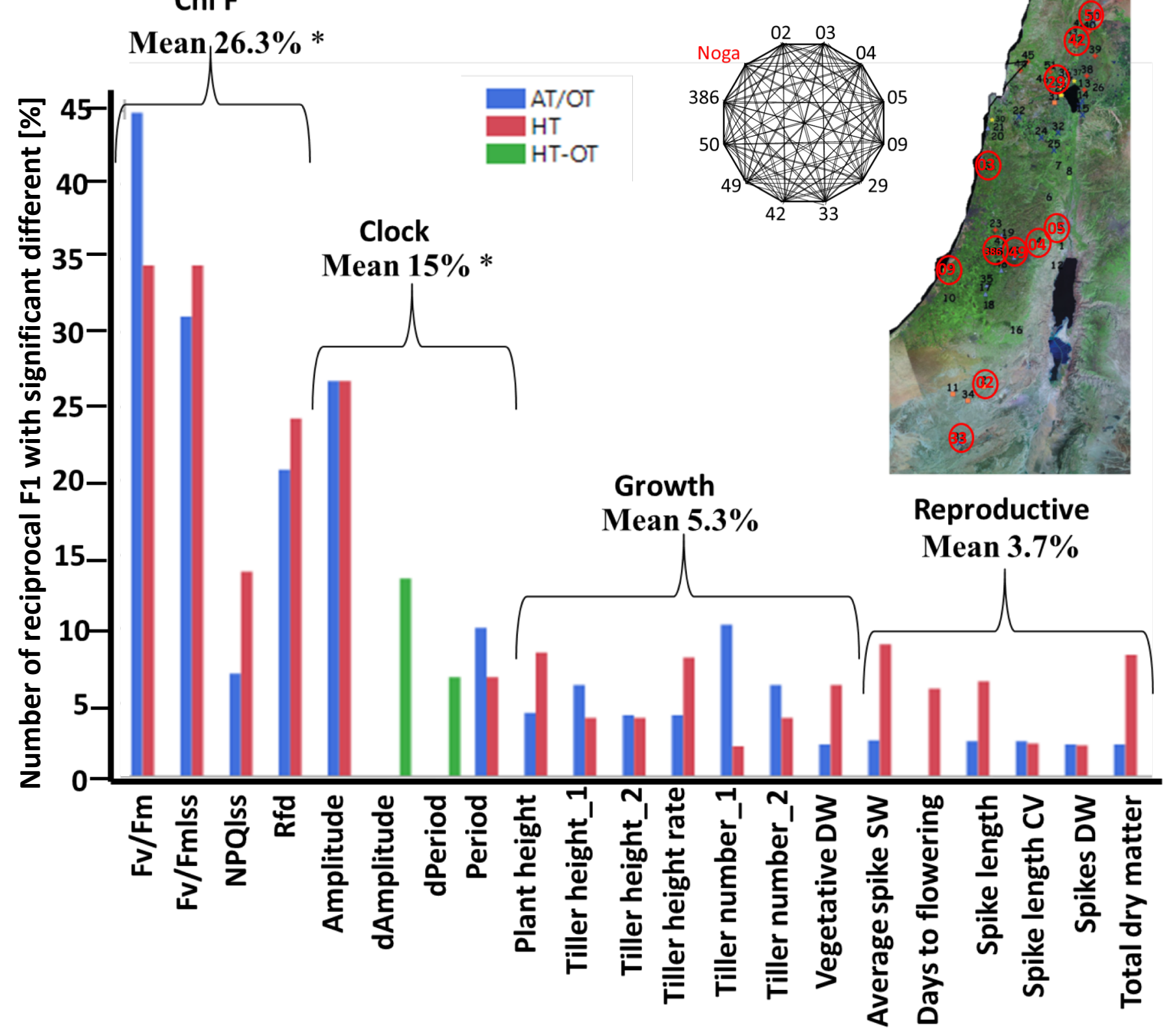

Figure 4 

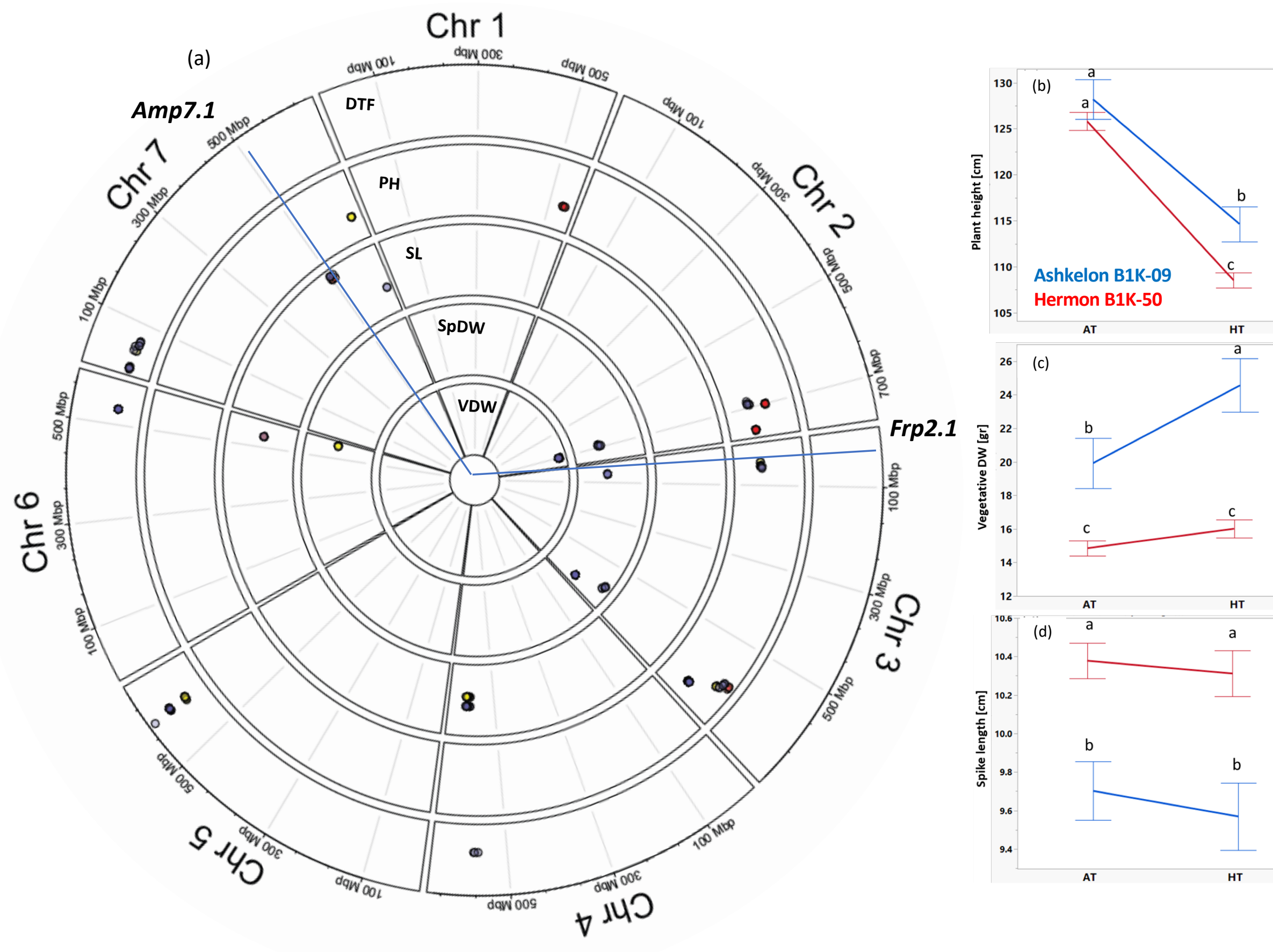

Figure 5

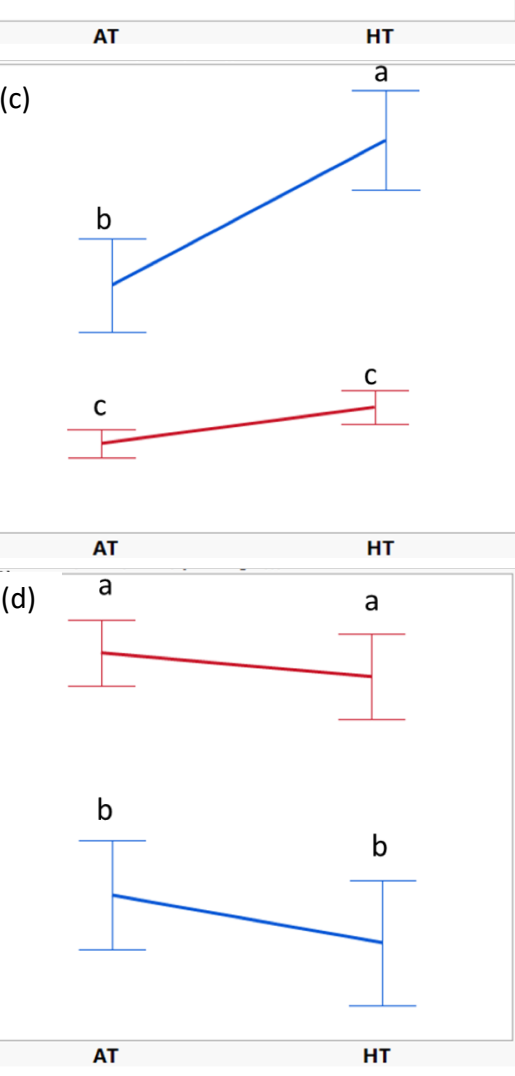


Figure 6

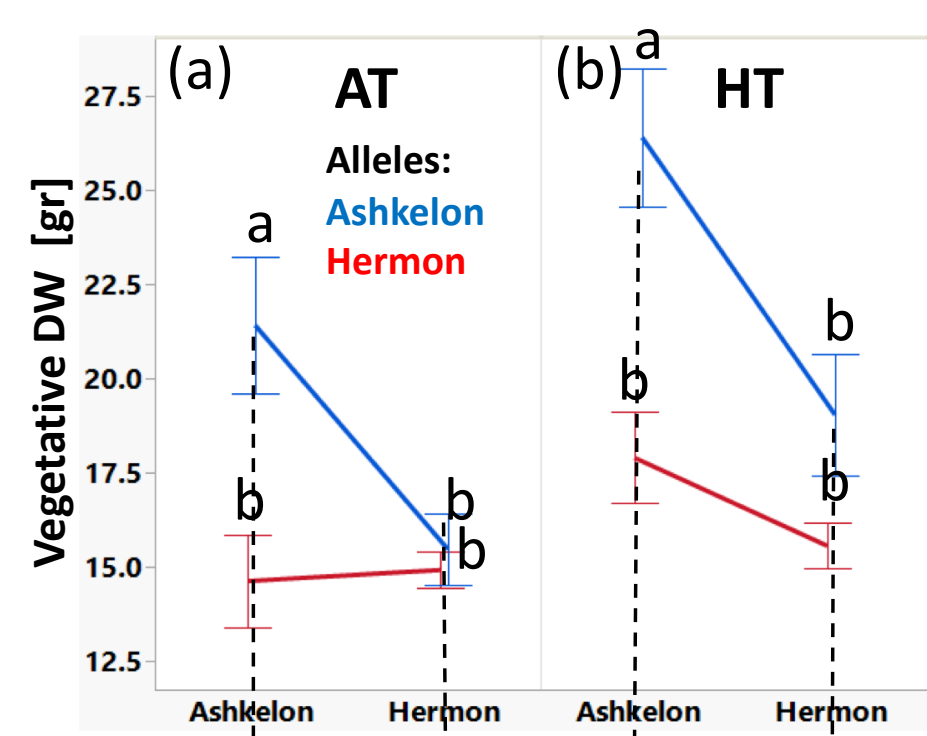

(e)
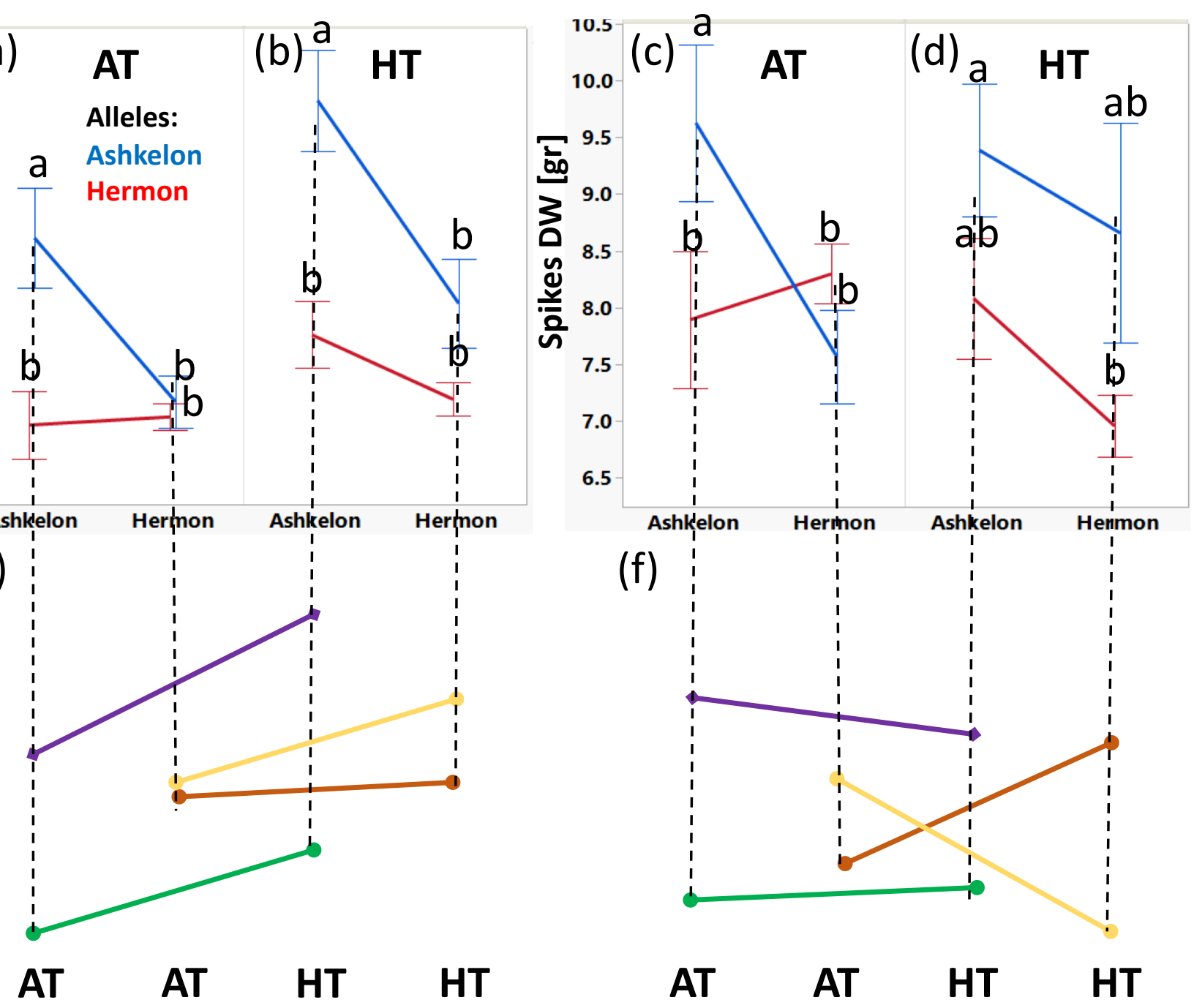

(f)

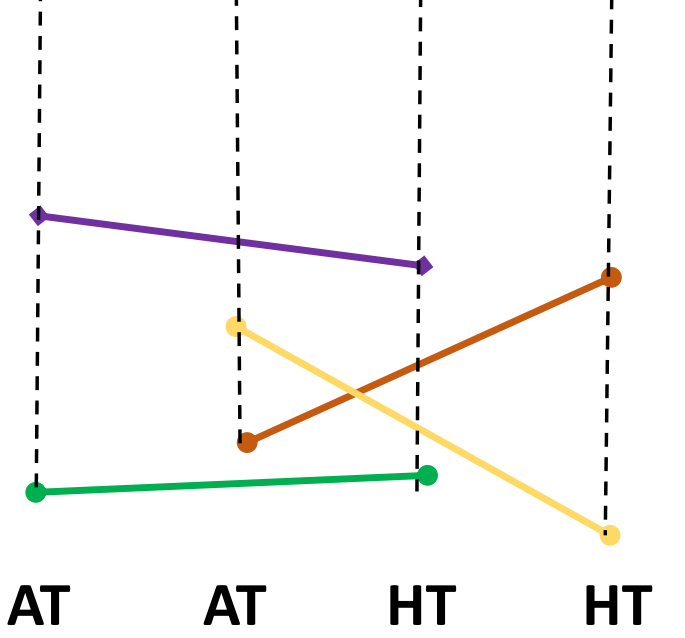




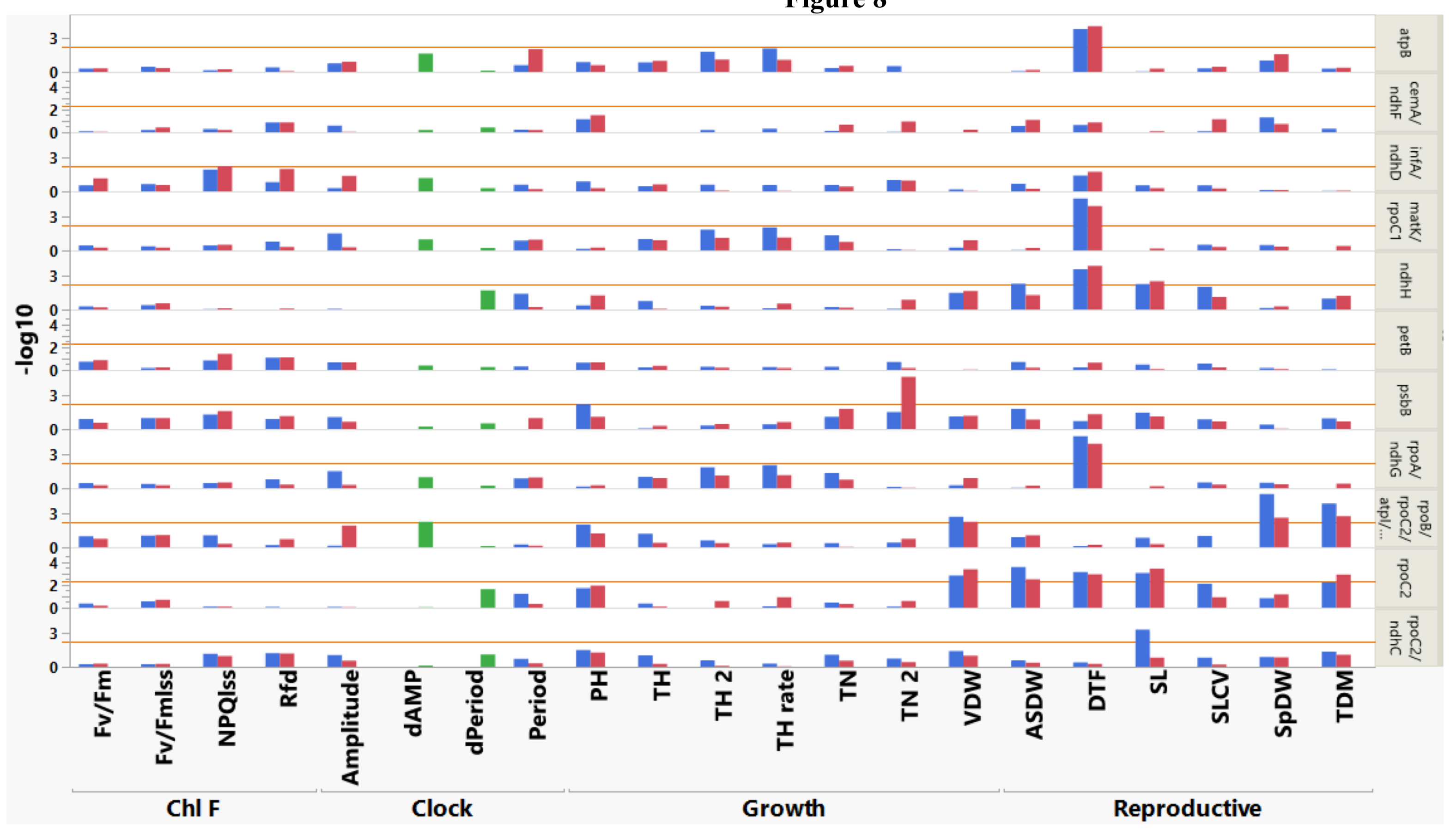




\section{Parsed Citations}

Andronis C, Barak S, Knowles SM, Sugano S, Tobin EM (2008) The Clock Protein CCA1 and the bZP Transcription Factor HY5 Physically Interact to Regulate Gene Expression in Arabidopsis. Mol Plant 1: 58-67

Google Scholar: Author Only Title Only Author and Title

Bdolach E, Prusty MR, Faigenboim-Doron A, Filichkin T, Helgerson L, Schmid KJ, Greiner S, Fridman E (2019) Thermal plasticity of the circadian clock is under nuclear and cytoplasmic control in wild barley. Plant Cell Environ. doi: 10.1111/pce.13606

Google Scholar: Author Only Title Only Author and Title

Bendix C, Marshall CM, Harmon FG (2015) Circadian clock genes universally control key agricultural traits. Mol Plant 8: 1135-1152

Google Scholar: Author Only Title Only Author and Title

Bineau E, Diouf I, Carretero Y, Duboscq R, Bitton F, Djari A, Zouine M, Causse M (2021) Genetic diversity of tomato response to heat stress at the QTL and transcriptome levels. Plant J. doi: 10.1111/tpj.15379

Google Scholar: Author Only Title Only Author and Title

Chen Y, Lübberstedt T (2010) Molecular basis of trait correlations. Trends Plant Sci 15: 454-461

Google Scholar: Author Only Title Only Author and Title

Dakhiya Y, Hussien D, Fridman E, Kiflawi M, Green R (2017) Correlations between circadian rhythms and growth in challenging environments. Plant Physiol 173: 1724-1734

Google Scholar: Author Only Title Only Author and Title

Ekiz H, Kiral AS, Akçin A, Simsek L (1998) Cytoplasmic effects on quality traits of bread wheat (Triticum aestivum L.). Euphytica 100: 189-196

Google Scholar: Author Only Title Only Author and Title

Flaconer DS, Mackay TF. (1996) Introduction to Quantitative Genetics, 4th ed. Pearson Education Limited, Harlow, United Kingdom Google Scholar: Author Only Title Only Author and Title

Flood PJ, Theeuwen TPJM, Schneeberger K, Keizer P, Kruijer W, Severing E, Kouklas E, Hageman JA, Wijjes R, Calvo-Baltanas V, et al (2020) Reciprocal cybrids reveal how organellar genomes affect plant phenotypes. Nat Plants 6: 13-21

Google Scholar: Author Only Title Only Author and Title

Frei U, Peiretti EG, Wenzel G (2003) Significance of cytoplasmic DNA in plant breeding. In J Janick, ed, Plant Breed. Rev. ohn Wiley \& Sons, Inc., Hoboken, pp 175-210

Google Scholar: Author Only Title Only Author and Title

Frei U, Peiretti EG, Wenzel G (2010) Significance of Cytoplasmic DNA in Plant Breeding. Plant Breed Rev. doi: 10.1002/9780470650226.ch4

Google Scholar: Author Only Title Only Author and Title

Fridman E (2015) Consequences of hybridization and heterozygosity on plant vigor and phenotypic stability. Plant Sci 232: 35-40

Google Scholar: Author Only Title Only Author and Title

Gajecka M, Marzec M, Chmielewska B, Jelonek J, Zbieszczyk J, Szarejko I (2021) Changes in plastid biogenesis leading to the formation of albino regenerants in barley microspore culture. BMC Plant Biol 21: 1-24

Google Scholar: Author Only Title Only Author and Title

Gellman MD, Turner JR (2020) Encyclopedia of Behavioral Medicine. Encycl Behav Med. doi: 10.1007/978-3-030-39903-0

Google Scholar: Author Only Title Only Author and Title

Goff S a (2011) A unifying theory for general multigenic heterosis: energy efficiency, protein metabolism, and implications for molecular breeding. New Phytol 189: 923-37

Google Scholar: Author Only Title Only Author and Title

Gordon VS, Staub JE (2011) Comparative analysis of chilling response in cucumber through plastidic and nuclear genetic effects component analysis. J Am Soc Hortic Sci 136: 256-264

Google Scholar: Author Only Title Only Author and Title

Gould PD, Diaz P, Hogben C, Kusakina J, Salem R, Hartwell J, Hall A(2009) Delayed fluorescence as a universal tool for the measurement of circadian rhythms in higher plants. Plant J 58: 893-901

Google Scholar: Author Only Title Only Author and Title

Hess WR, Prombona S, Fieder B, Subramanian AR, Borner T (1993) Chloroplast rps15 and the rpoB/C1/C2 gene cluster are strongly transcribed in ribosome-deficient plastids: Evidence for a functioning non-chloroplast-encoded RNA polymerase. EMBO J 12: 563-571 Google Scholar: Author Only Title Only Author and Title

Hubner S, HÖffken M, Oren E, Haseneyer G, Stein N, Graner A, Schmid K, Fridman E (2009) Strong correlation of wild barley (Hordeum spontaneum) population structure with temperature and precipitation variation. Mol Ecol 18: 1523-1536

Google Scholar: Author Only Title Only Author and Title 
Izawa T, Mihara M, Suzuki Y, Gupta M, Itoh H, Nagano AJ, Motoyama R, Sawada Y, Yano M, Hirai MY, et al (2011) Os-GIGANTEA confers robust diurnal rhythms on the global transcriptome of rice in the field. Plant Cell 23: 1741-1755

Google Scholar: Author Only Title Only Author and Title

Kromdijk J, Głowacka K, Leonelli L, Gabilly ST, Iwai M, Niyogi KK, Long SP (2016) Improving photosynthesis and crop productivity by accelerating recovery from photoprotection. Science (80-). doi: 10.1126/science.aai8878

Google Scholar: Author Only Title Only Author and Title

Lee S, Lee T, Yang S, Lee I (2020) BarleyNet : ANetwork-Based Functional Omics Analysis Server for Cultivated Barley, Hordeum vulgare L . 11: 1-11

Google Scholar: Author Only Title Only Author and Title

Li H, Ye G, Wang J (2007) A modified algorithm for the improvement of composite interval mapping. Genetics 175: 361-374

Google Scholar: Author Only Title Only Author and Title

Malosetti M, Ribaut JM, van Eeuwijk FA(2013) The statistical analysis of multi-environment data: Modeling genotype-by-environment interaction and its genetic basis. Front Physiol. doi: 10.3389/fphys.2013.00044

Google Scholar: Author Only Title Only Author and Title

Maurer A, Draba V, Jiang Y, Schnaithmann F, Sharma R, Schumann E, Kilian B, Reif JC, Pillen K (2015) Modelling the genetic architecture of flowering time control in barley through nested association mapping. BMC Genomics 16: 1-12

Google Scholar: Author Only Title Only Author and Title

Meng L, Li H, Zhang L, Wang J (2015) QTL IciMapping: Integrated software for genetic linkage map construction and quantitative trait locus mapping in biparental populations. Crop J 3: 269-283

Google Scholar: Author Only Title Only Author and Title

Naithani S, Gupta P, Preece J, Eustachio PD, Elser JL, Garg P, Dikeman DA, Kiff J, Cook J, Olson A, et al (2020) Plant Reactome : a knowledgebase and resource for comparative pathway analysis. 48: 1093-1103

Google Scholar: Author Only Title Only Author and Title

Nakazato I, Okuno M, Yamamoto H, Tamura Y, Itoh T, Shikanai T, Takanashi H, Tsutsumi N, Arimura S ichi (2021) Targeted base editing in the plastid genome of Arabidopsis thaliana. Nat Plants. doi: 10.1038/s41477-021-00954-6

Google Scholar: Author Only Title Only Author and Title

Noordally ZB, Ishii K, Atkins KA, Wetherill SJ, Kusakina J, Walton EJ, Kato M, Azuma M, Tanaka K, Hanaoka M, et al (2013) Circadian control of chloroplast transcription by a nuclear-encoded timing signal. Nature 339: 1316-9

Google Scholar: Author Only Title Only Author and Title

Novakazi F, Krusell L, Jensen JD, Orabi J, Jahoor A, Bengtsson T, On Behalf Of The Ppp Barley Consortium (2020) You Had Me at "MAGIC"!: Four Barley MAGIC Populations Reveal Novel Resistance QTL for Powdery Mildew. Genes (Basel). doi:

10.3390/genes11121512

Google Scholar: Author Only Title Only Author and Title

Panter PE, Muranaka T, Cuitun-Coronado D, Graham CA Yochikawa A, Kudoh H, Dodd AN (2019) Circadian Regulation of the Plant Transcriptome Under Natural Conditions. Front Genet 10: 1-12

Google Scholar: Author Only Title Only Author and Title

Pfannschmidt T, Blanvillain R, Merendino L, Courtois F, Chevalier F, Liebers M, Grübler B, Hommel E, Lerbs-Mache S (2015) Plastid RNA polymerases: Orchestration of enzymes with different evolutionary origins controls chloroplast biogenesis during the plant life cycle. J Exp Bot. doi: 10.1093/jxb/erv415

Google Scholar: Author Only Title Only Author and Title

Prusty MR, Bdolach E, Yamamoto E, Tiwari LD, Silberman R, Doron-Faigenbaum A, Neyhart JL, Bonfil D, Kashkush K, Pillen K, et al (2021) Genetic loci mediating circadian clock output plasticity and crop productivity under barley domestication. New Phytol. doi:

10.1111/nph.17284

Google Scholar: Author Only Title Only Author and Title

Ravi M, Marimuthu MPA, Tan EH, Maheshwari S, Henry IM, Marin-Rodriguez B, Urtecho G, Tan J, Thornhill K, Zhu F, et al (2014) A haploid genetics toolbox for Arabidopsis thaliana. Nat Commun. doi: 10.1038/ncomms6334

Google Scholar: Author Only Title Only Author and Title

Rees H, Duncan S, Gould P, Wells R, Greenwood M, Brabbs T, Hall A(2019) Ahigh-throughput delayed fluorescence method reveals underlying differences in the control of circadian rhythms in Triticum aestivum and Brassica napus. Plant Methods. doi:

10.1186/s13007-019-0436-6

Google Scholar: Author Only Title Only Author and Title

Rees H, Joynson R, Brown JKM, Hall A(2021) Naturally occurring circadian rhythm variation associated with clock gene loci in Swedish Arabidopsis accessions. Plant Cell Environ. doi: 10.1111/pce.13941

Google Scholar: Author Only Title Only Author and Title

Sanetomo R, Gebhardt C (2015) Cytoplasmic genome types of European potatoes and their effects on complex agronomic traits. BMC Plant Biol 15: 162 
Schnaithmann F, Kopahnke D, Pillen K (2014) A first step toward the development of a barley NAM population and its utilization to detect QTLs conferring leaf rust seedling resistance. Theor Appl Genet 127: 1513-1525

Google Scholar: Author Only Title Only Author and Title

Steiner S, Schröter Y, Pfalz J, Pfannschmidt T (2011) Identification of essential subunits in the plastid-encoded RNA polymerase complex reveals building Blocks for Proper plastid development. Plant Physiol. doi: 10.1104/pp.111.184515

Google Scholar: Author Only Title Only Author and Title

Tang Z, Hu W, Huang J, Lu X, Yang Z, Lei S, Zhang Y, Xu C (2014) Potential involvement of maternal cytoplasm in the regulation of flowering time via interaction with nuclear genes in maize. Crop Sci. doi: 10.2135/cropsci2013.07.0459

Google Scholar: Author Only Title Only Author and Title

Tindall AJ, Waller J, Greenwood M, Gould PD, Hartwell J, Hall A(2015) Acomparison of high-throughput techniques for assaying circadian rhythms in plants. Plant Methods 11: 32

Google Scholar: Author Only Title Only Author and Title

Vishnukiran T, Neeraja CN, Jaldhani V, Vijayalakshmi P, Raghuveer Rao P, Subrahmanyam D, Voleti SR (2020) Amajor pleiotropic QTL identified for yield components and nitrogen content in rice (Oryza sativa L.) under differential nitrogen field conditions. PLoS One 15: 1-22

Google Scholar: Author Only Title Only Author and Title

Zelinski T, Moore AM, Troup E, Halliday KJ, Millar AJ (2014) Strengths and limitations of period estimation methods for circadian data. PLoS One. doi: 10.1371/journal.pone.0096462

Google Scholar: Author Only Title Only Author and Title 